\title{
Hierarchy of the factors influencing the broad-scale waterbirds functional diversity gradients in temperate China
}

\author{
Yamian Zhang ${ }^{1}$, Wenzhuo Tan ${ }^{1}$, Li Wen ${ }^{2}$, QIng Zeng ${ }^{1}$, Haitao Tian ${ }^{1}$, Yifei Jia ${ }^{1}$, and \\ Guangchun Lei ${ }^{1}$ \\ ${ }^{1}$ Beijing Forestry University \\ ${ }^{2}$ NSW Department of Planning Industry and Environment
}

May 18, 2020

\begin{abstract}
Geographical gradients in species diversity have long fascinated biogeographers and ecologists. However, the extent and generality of the positive/negative effects of the important factors governing functional diversity (FD) patterns are still debated, especially for the freshwater domain. We examined lake productivity and functional richness (FRic) of waterbirds sampled from 35 lakes and reservoirs in northern China with a geographic coverage of over 5 million $\mathrm{km} 2$. We used structural equation modelling (SEM) to explore the causal relationships between geographic position, climate, lake productivity and waterbirds FRic. We found unambiguous altitudinal and longitudinal gradients in lake productivity and waterbirds FD, which were strongly mediated by local environmental factors. Specifically, we found 1) lake productivity increased northeast but decreased with altitude, and the observed gradients were driven by climate and nutrient availability, with $93 \%$ of variation explained in the individual SEM; 2) waterbirds FD showed similar geographic and elevational gradients.; the environmental factors which had direct and/or indirect effects on these geographic and elevational gradients included climate, lake productivity and morphology, which collectively explained more than $56 \%$ of the variation in waterbirds $\mathrm{FD}$; and 3$)$ a significant $(\mathrm{P}=0.029)$ causality between lake productivity and waterbirds FD was confirmed. Nevertheless, the causality link was relatively weak in comparison with climate and lake area (standardized path coefficient was $0.65,0.21$, and 0.17 for climate, area, and productivity, respectively). Through articulating the dominant causality paths, our results could contribute to the mechanistic explanations underlying the observed broad-scale biodiversity gradients.
\end{abstract}

\section{Introduction}

One of the oldest and most important macroecology patterns is the spatial variability in biodiversity over broad geographical extents (Field et al., 2009; Hawkins, 2001; Stein, Gerstner, \& Kreft, 2014), an appropriate knowledge of which is an essential key to guarantee the provision of multiple ecosystem services (Benedetti et al., 2020). The planet Earth shows striking gradients in the diversity of plants and animals, from high biodiversity in the tropics to low biodiversity in polar and high-mountain regions (Gaston, 2000; Rosenzweig, 1995; Whittaker, Nogues-Bravo, \& Araujo, 2007; Willig, Kaufman, \& Stevens, 2003). Due to the alarming rate of biodiversity loss in the last decades caused by anthropogenic interruption (Prescott et al., 2016; Waide et al., 1999), a modern resurgence of interests in taxonomic diversity patterns is likely to contribute important insights for developing a more general theory of species diversity (Castro-Insua, Gómez-Rodriguez, \& Baselga, 2016). Studies in the past decades has documented the broad-scale spatial patterns of species diversity, and explored the mechanisms for such patterns, leading to conceptual insight on the biogeographical variation of species diversity (Devictor et al., 2010; Field et al., 2009; Gaston, 2000). For example, diversity is often highest at intermediate levels of ecosystem productivity (Grime, 1973; Mittelbach et al., 2001; Waide et al., 
1999), and species diversity generally increases with habitat area (MacArthur \& Wilson, 1967; Rosenzweig, 1995). In addition, environmental heterogeneity is considered as a universal driver of species diversity across taxa, biomes and spatial scales (Stein et al., 2014). Importantly, both theoretical considerations and empirical analyses suggest that patterns are likely scale dependent (Field et al., 2009; Mittelbach et al., 2001; Mouchet et al., 2015).

Most macroecology researches have been focused on terrestrial ecosystems (Currie \& Paquin, 1987; Qian, Ricklefs, \& White, 2005), and relative fewer studies have explored geographic biodiversity gradients and the underling mechanisms for aquatic ecosystems (Astorga, Heino, Luoto, \& Muotka, 2011; Barbour \& Brown, 1974; Heino, 2002, 2011; Irz, Argillier, \& Thierry, 2004; Jacobsen, 2004), especially the aquatic ecosystems in the arid and semi-arid region, which provide important habitat for diverse species and water resource for human living (Williams, 1999). Moreover, the geographical distribution of study sites is strongly biased towards Europe and North America, with particularly poor coverage in Asia (Field et al., 2009; Fu, Wu, Wang, Lei, \& Chen, 2004). Study of species diversity in aquatic ecosystems is as essential as in their terrestrial counterparts (Stendera et al., 2012). Declines in biodiversity are far greater in freshwaters than in most terrestrial ecosystems (Sala et al., 2000), and freshwater ecosystems may well be the most endangered ecosystems in the world (Dudgeon et al., 2006; Millennium Ecosystem Assessment, 2005). In addition, the actual rates of freshwater species extinction due to human interruptions are much higher than natural extinction rates (Naiman \& Dudgeon, 2011). Therefore, a better understanding of the global freshwater diversity gradients and the major environmental drivers remains a major topic (Heino, 2011); and such studies serve to address some fundamental questions for conserving freshwater taxa (Tisseuil et al., 2013).

In addition, biodiversity assessments are an important component of conservation planning and increasingly used to identify land-use management practices that maximise both evolutionary value and ecosystem function (Chapman, Tobias, Edwards, Davies, \& Vamosi, 2018). Key requirements are to maintain community resilience to environmental disturbance and to preserve ecosystem functions and services across time and space (Socolar, Gilroy, Kunin, \& Edwards, 2016). Consequently, it is often proposed that we need to look beyond merely conserving species richness towards maintaining the maximum diversity of evolutionary lineages and associated ecological functions (Bregman et al., 2016). The idea that functional diversity or functional complementarity performs better than species richness as predictors of ecosystem functions is supported by a range of empirical studies (Flynn, Mirotchnick, Jain, Palmer, \& Naeem, 2011; Frund, Dormann, Holzschuh, \& Tscharntke, 2013; Petchey \& Gaston, 2007). Functional diversity (FD) is a biodiversity component that represents the extent of the functional differences among species based on the distinction of their morphological, physiological and ecological traits (Petchey \& Gaston, 2006). Species loss may lead to a reduction in FD depending on the intrinsic redundancy of assemblages (Flynn et al., 2009; Petchey, Evans, Fishburn, \& Gaston, 2007). A decrease on the FD of local and regional assemblages could have dramatic consequences for ecosystem functioning because the traits of species, not just the number of taxonomic units, ultimately drive biodiversity-ecosystem functioning relationships (Diaz \& Cabido, 2001; Hooper et al., 2005). Worldwide, strong geographic differences exist in the ecological attributes of birds (Kissling, Sekercioglu, \& Jetz, 2012). Thus, we ask how these factors combined to affect the diversity of species assemblages under different environmental conditions.

Waterbirds are ubiquitous components of freshwater systems, and their diversity and abundance have long been recognized as suitable bioindicators of environmental change in aquatic systems (Caro \& O'Doherty, 1999; Wen, Saintilan, Reid, \& Colloff, 2016) and serves multiple significant functional roles in ecosystems (Barbet-Massin \& Jetz, 2015) (Figure 1). However, as with other freshwater biota, macroecological studies of environmental drivers of waterbirds diversity are rare (Shah, Domisch, Pauls, Haase, \& Jähnig, 2014; Stendera et al., 2012; Zeng et al., 2019). It is unclear whether similar latitudinal and other broad geographical (e.g. altitudinal) gradients apply to waterbirds as well. In a recent review, Heino (2011) found no clear latitudinal gradients at regional scale while species richness typically attains highest levels in mountainous regions. Using river basins as the spatial unit, however, Tisseuil et al. (2013) found that the 'climate/productivity' hypothesis (Field et al., 2009) explained large portion of geographic variance in waterbirds richness, which is consistent to land avian species (Storch et al., 2006). Several factors are known to affect waterbirds diversity 
at a local scale, such as lake productivity, lake size, and habitat heterogeneity (Barbour \& Brown, 1974; Cintra, 2015; Xia et al., 2016). Linking these local scale variables with broad-scale geographical variations in an integrative analysis framework could potentially articulate the leading processes underlying the regional and global waterbirds richness patterns.

Lakes are ideal systems for studying the relationship between species richness and productivity (Dodson, Arnott, \& Cottingham, 2000). It provides a unique system to examine macro-ecological pattern involving geographic and elevational gradients in inland aquatic systems. In this study, we apply multiple regression analysis and structural equation models (SEM) to lake productivity and waterbirds FD data collected from 35 lakes and reservoirs across the temperate zone of arid and semi-arid China to examine macro-ecological pattern involving geographic and elevational gradients in inland aquatic systems. Our primary goal is to test the causal path of geographic location climate lake productivity waterbirds FD. In particular, we first develop separate models for lake productivity and waterbirds FD to compare the dominant factors controlling the gradients of the two indicators. We then build an integrative SEM with explicit causality from productivity to waterbirds diversity to quantify the effect of lake productivity on waterbirds FD. Lake productivity is often a strong predictor of freshwater biodiversity (Dodson et al., 2000), including aquatic animals (and zooplankton as well) (Chase \& Leibold, 2002) and phytoplankton (Stomp, Huisman, Mittelbach, Litchman, \& Klausmeier, 2011). But its effect on waterbirds has rarely been tested. The productivity-richness hypothesis suggests a positive effect of primary productivity on species richness by allowing larger populations to persist, thereby reducing extinction risk and supporting a higher diversity of niche specialists (Tittensor et al., 2010; Willig et al., 2003). In this context, a significantly positive path coefficient from lake productivity to waterbirds could provide strong support to the productivity-richness hypothesis. However, a weak or no causal link between the two might suggest that waterbirds, not like other aquatic biota like fish (Dodson, 2008) that is constrained by water, have access to other energy sources; and their distribution is governed by other broad scale factors. In this study, we applied FD metrics to waterbird communities sampled in 35 lakes across the whole temperate arid and semi-arid northern China to test the productivity-richness hypothesis, and more importantly, to fill in the gaps in our understanding of ecological patterns in aquatic ecosystems across a large geographical scale.

\section{Materials and methods}

\section{Study sites}

We sampled a total of 35 lakes and reservoirs across the temperate zone of China (latitude $34.60^{\circ}$ to $46.06^{\circ}$, longitude $85.69^{\circ}$ to $124.29^{\circ}$, Figure 2). The study area covers more than 5 million $\mathrm{km}^{2}$, including a range of landforms such as mountains, hills, plateaus, and plains with altitude ranging from $22.61 \mathrm{~m}$ to 4818.10 $\mathrm{m}$, which have large precipitation and temperature gradients. The total area of all the lakes is $508,288.1$ ha, ranges from about 70 to 98,800 ha. Mean depth of the lakes ranges from 0.05 to $30.00 \mathrm{~m}$. Most of the lakes are located in the arid and semi-arid region of China, which are relatively independent wetland ecosystems (Wang \& Dou, 1998). They provide critical habitats for diverse species (e.g. important breeding and staging sites for waterbirds, some are also used as wintering ground, like Hengshui Lake). The environment in the semi-arid area is sensitive to climate variation (Gong, Shi, \& Wang, 2004). Human uses of the lakes mainly include fishery, tourism, water source for irrigation, and reed harvest.

\section{Data collection}

Data were collected from 35 lakes and reservoirs during the summers of 2011-2016. The lakes were sampled one to three times, with most of them sampled once in summer. In each lake, water samples were taken on the same day as waterbirds survey during daylight hours. 


\section{Waterbirds surveys}

Waterbirds were surveyed using transect line method to cover the lakes. Fixed transects with variable lengths were established in each lake and reservoir. Based on the size of each lake and reservoir, the transect length varied from 1 to $5 \mathrm{~km}$ and the perpendicular searching distance varied from 0.1 to $0.6 \mathrm{~km}$. We surveyed the transects on foot with constant speed by using binoculars $(8 \times 42)$ and telescopes (Swarovski ATS 80 HD $20-60 \times 80)$. To increase detectability, the surveys were carried out on clear days during daytime and there were at least two fully trained observers for each transect. Visual and/or verbal communication enabled us to avoid duplicate recordings of the same flock of waterbirds by the observers. Waterbirds were all identified to species level. Lists of waterbirds species recorded by the nature reserves and published papers were also collected and incorporated.

\section{Functional trait data}

To estimate functional diversity, we collected biometric trait data that describe key ecological attributes of species from published literature for all 148 species. We collected 16 traits for each bird species, including generation length (the average age of breeding individuals), clutch size (number of eggs), incubation times, body size, body mass, wingspan, migratory types (full migration, altitudinal migration, and not migration), breeding habitat range, diet (percentage of scavenger, and invertebrate, fish, seed, fruit and other plant materials), habitat mode (percentage usage of water, riparian, and ground), and pelagic species (0/1) (Table 1). These selected traits measure many aspects of resource used by birds, such as the quantity and the quality of resource consumed (Petchey \& Gaston, 2007), as well as the fitness of the species such as reproduction strategies and generation length (Luck, Andrew, Lisa, \& Davies, 2013). For example, body mass is highly related to birds' energy requirements (Blendinger \& Villegas, 2011). Diet is related to ecosystem functions such as seed dispersal and food-web structure (Sekercioglu, 2006). The main sources of the trait measurements are Planet of Birds, BirdLife International, and a database compiled by Wilman et al. (2014) (Table 1). Any missing data were filled based on information in the ornithological literature, such as the Handbook of the Birds of the World (http://www.hbw.com/). A brief summary is available in the Appendix S1.

We used functional richness (FRic) as the measure of functional diversity. FRic represents the amount of functional space filled by the community (Villéger, Mason, \& Mouillot, 2008). A community with high FRic would be one with many traits (and potentially high utilization of resources), whereas one with lower FRic might have some traits missing, suggesting that some niches are completely empty (Prescott et al., 2016).

\section{Lake chemical characteristics and morphology}

Indicators for lake chemical characteristics include total nitrogen (TN), total phosphorus (TP) and chlorophylla (Chl-a). Water samples for TN and TP in each lake were collected and preserved using 100-ml jars on the same day with waterbirds surveys. All the water samples were sent to and processed in lab by using Ultrospec 6300 pro spectrophotometer (GE Healthcare, America). Water samples for chlorophylla (Chl-a) concentration were collected synchronously on site. We used 2-litre bottles to collect water samples in each lake and reservoir and then filtered the water by using GF/C filter membrane, each filter membrane was filtered with $500 \mathrm{~mL}$ water and three filter membranes $\left(3^{*} 500 \mathrm{~mL}\right)$ were requested for every sampling point. All water samples and filter membranes were preserved in $<5$ refrigerator and sent to lab for further test by using Ultrospec 6300 pro spectrophotometer (GE Healthcare, America). Sample size ranges from 3 to 18 based on the area of lake. We set three, six, nine, 12 and 18 sampling points for lakes with area $<10,000$ ha, 10,000-20,000 ha, 20,001-30,000 ha, 30,001-50,000 ha and >50,000 ha, respectively. Surface area of each

lake and reservoir was calculated from remote sensing interpretation by using Google Earth images from year 2013 to 2016 .

\section{Climatic and geographical variables}

To define the climate of the lakes, we used the 30 seconds WorldClim bioclimatic variables, which were downloaded from WorldClim website, publicly available athttps://www.worldclim.org/data/worldclim21.html. The 
following bioclimatic variables were included in the study based on collinearity test (see below): mean diurnal range (T1, mean of monthly (max temp-min temp)), mean temperature of the wettest quarter (T2), mean temperature of the warmest quarter (T3), annual total precipitation (P1), precipitation of the driest month (P2), precipitation of the warmest quarter (P3), and precipitation of the coldest quarter (P4). The variables of climate are spatial means of each lake.

Altitudes of the sampled lakes were retrieved from GPS Visualizer on site. Mean geographical coordinates of each site were calculated from remote sensing interpretation by using Google Earth images of each lake and reservoir between years 2013 to 2016. The data of the 35 lakes and reservoirs used in this paper are provided in the Appendix S2.

\section{Data analyses}

Our working hypothesis is that large-scale pattern of high trophic level species (waterbirds in this study) diversity can be interpreted as a multilevel biogeographical pattern. That is, we envision that the species diversity of a lake is to a large extent determined by local environmental factors (e.g. nutrients, lake surface area), and that these local environmental factors in turn vary along biogeographical gradients. This nested structure is reflected in our data analysis.

We combined our own survey data and historical records to compile a waterbirds community dataset for each lake. FD was then calculated based on the compiled community data set. It is necessary to have several years of observation because the species observed in a lake could vary from year to year. In addition, we used the total chlorophyll $a$ proxy of primary productivity (Eppley, Stewart, Abbott, \& Heyman, 1985; Falkowski \& Raven, 2013).

\section{Multiple linear regression -relationships between geography, lake productivity and waterbirds functional diversity}

We used stepwise multiple regression with forward selection of variables to identify the most important local environmental variables explaining waterbirds FD in the 35 lakes and reservoirs. Environmental variables were $\log _{10}$-transformed if this resulted in a more uniform spread of data points. In addition, collinearity between variables was also checked based on variance inflation factor by using the VIF function with package "car" (Fox et al., 2012) in R software (R Development Core Team, 2019). Environmental variables tested in the multiple regression analysis were surface area of the lake (ha), total nitrogen (mg.L $\mathrm{L}^{-1}$ ), total phosphorus (mg. $\left.\mathrm{L}^{-1}\right)$ and lake productivity (mg.m- $\left.{ }^{3}\right)$, mean diurnal range (), mean temperature of the wettest quarter (), mean temperature of the warmest quarter (), annual total precipitation (mm), precipitation of driest month $(\mathrm{mm})$, and precipitation of the warmest quarter $(\mathrm{mm})$. We used the same stepwise multiple regression approach to investigate how each of these local environmental variables varied with the geographical coordinates of latitude, longitude and altitude $(\mathrm{m})$. The analysis was performed using $\mathrm{R}$ version 3.6.1 ( $\mathrm{R}$ Development Core Team, 2019).

\section{Structural equation modeling - exploring the drivers of lake productivity and waterbirds richness}

To gain further understanding of the linkages between waterbirds FD, productivity and environmental variables, we modeled lake productivity and waterbirds functional richness (FRic) in an integrated manner within the structural equation modeling (SEM) framework. SEM is a collection of procedures whereby complex hypotheses, particularly those involving networks of path relations, are evaluated against multivariate data (Grace, 2006). The resulting estimates for path coefficients in structural equation models represent the implied sensitivities of response variables to variations in individual predictors (Grace et al., 2012). We started with an initial SEM that included all plausible pathways between waterbirds functional diversity, the selected set of local environmental variables, and the geographical coordinates of the lakes. Our first attempt with the initial model revealed that it was under-identified, meaning that there was some redundancy such 
that it was not possible to estimate all of the model's parameters. We therefore investigated the statistical relationships among the variables included in the model to identify possible redundancies. Subsequently, we fitted two separate SEMs for lake productivity and waterbirds functional diversity, and an integrated SEM revealing the correlation between the two factors. The significance of each path-coefficient was tested 1000 bootstrapped resamples. We reported the standardized coefficients that can be directly compared to make inferences about the relative strength of relationships (Grace \& Bollen, 2005). The structural equation analyses were performed using R version 3.6.1 (R Development Core Team, 2019) with package "Lavaan" version 3.1-3 (Rosseel et al., 2015).

\section{Results}

A total of 148 species, belonging to six orders and 19 families were recorded in this study (Appendix S1). The highest number of species was from the family Scolopacidae (37 species), followed by Anatidae (34 species). Some families such as Phalacrocoracidae, Threskiornithidae and Rostratulidae only had one species each. In addition, among the 35 lakes and reservoirs surveyed, number of species ranged from four to 113 species, with the highest species richness recorded in lakes and reservoirs located in Hubei Province and Beijing (eastern China), and lowest species richness recorded in lakes and reservoirs located in Inner Mongolia and Qinghai Province (western China) (Appendix S2).

\section{Geographical patterns of waterbirds species richness and functional diversity}

Waterbirds species richness showed remarkable geographical distribution gradients (Figure 3a). Generally, higher waterbirds species richness was found in lakes of the northern and eastern part of China. Lower species richness was found at higher altitude in the west. Similar pattern was found in waterbirds FRic (Figure 3b). Linear regression showed that FRic increased with latitude and longitude (Figure 4a, 3b), but decreased with altitude (Figure 4c). Furthermore, multiple regression analysis showed that lake area, mean temperature of the wettest quarter, annual total precipitation, and precipitation of the warmest quarter had significant effects on waterbirds FRic, explaining greater than $71 \%$ of the total variation in the dataset (Table 1). More specifically, FRic increased with lake area, mean temperature of the wettest quarter, and annual total precipitation, but decreased with precipitation of the warmest quarter.

Site-specific environmental variables including lake productivity, mean diurnal range, mean temperature of the wettest quarter, mean temperature of the warmest quarter, annual total precipitation, precipitation of the driest month, precipitation of the warmest quarter and precipitation of the coldest quarter showed large-scale variation across the landscape of north China. For example, lake productivity decreased with altitude; mean diurnal range, mean temperature of the wettest quarter, and mean temperature of the warmest quarter decreased with latitude, longitude and altitude; while annual total precipitation of the driest month, precipitation of the warmest quarter and precipitation of the coldest quarter increased with longitude (Table 2).

\section{Final structural equation models}

Three SEMs were fitted: one for lake productivity, one for waterbirds FD, and an integrated one that included both lake productivity and waterbirds FD to explicitly test the causal link between them. All three models converged successfully (Figure 5-7), and achieved adequate fit with CFI (Comparative fit index) of 0.90, 0.98 and 0.90 for the productivity SEM, waterbird FD SEM and integrated SEM, respectively (Hu \& Bentler, 1999). These models had similar hierarchical structure, in which the responsible variable (lake productivity or waterbirds FD) was modelled by a few latent factors. These latent factors were in term defined by the observed variables. In all models, two latent factors were common: geographic position and climate. The geographic position was measured by the latitude and longitude of the central point of the lake and its average elevation. The climate was defined by using spatial mean of seven bioclimatic variables with 
low correlation (checked using VIF). In addition, a causality from geographic position to climate condition was specified in all SEMs.

\section{Determinates of Lake Productivity}

The three latent factors (i.e. geographic position, climate, and nutrient in the lake) were all included in the SEM. The three factors collectively explained $93 \%$ of the variation in lake productivity (Figure 5 ). Lake nutrient level, which was defined by water TP and TN concentration, had the largest effects on productivity, followed by climate (standardized path coefficient $=0.93$ and 0.77 for nutrient and climate, respectively, Figure 5). The effects of geographic position on lake productivity was indirect and realized through its influence on climatic condition; and had a standardized path coefficient of $0.16(0.77 \times 0.21)$.

Lake productivity decreased with elevation (path coefficient $=-0.93 \times 0.77 \times 0.07=-019$ ) and increased with both latitude and longitude with comparable path coefficient ( 0.12 and 0.13 for latitude and longitude, respectively, Figure 5). For the measured bioclimatic variables, while all variables related to precipitation as well as T2 and T3 had positive effect on lake productivity, the impact of temperature diurnal range was negative with a path coefficient of $-0.22(-0.83 \times 0.27)$. Lake productivity was positively related with nutrient; and the effect of TP level was slightly larger than that of TN (standardized path coefficient 0.52 and 0.40 for TP and TN, respectively, Figure 5).

\section{Determinates of waterbirds functional diversity}

Similar to the lake productivity model, the three latent factors (geographic position, climate, and lake morphology in the lake) were all included in the SEM, collectively explaining $52 \%$ of the variation in waterbirds FD (Figure 6). In comparison with lake morphology, climate had higher effects on waterbirds FD (path coefficient $=0.69$ and 0.21 for climate and morphology, respectively, Figure 6 ). The effects of geographic position on waterbirds distribution was indirect through climate with an effect of $0.57(0.82 \times 0.69=0.56)$. Based on the standardized model coefficients, climate condition had the strongest effects on waterbirds FD, followed by geographic position and lake morphology (the coefficients are $0.69,0.57$, and 0.21 for climate, geographic position and lake morphology, respectively, Figure 6).

Waterbirds FD decreased with elevation (path coefficient $=-0.59 \times 0.82 \times 0.69=-0.33$ ), and increased with both latitude and longitude, with longitude showing much stronger effect than latitude (path coefficients were 0.61 and 0.23 respectively, Figure 6 ). For the measured bioclimatic variables, similar to the productivity model, while all precipitation variables ad well as T2 and T3 had positive effect on waterbirds FD, the impact of temperature diurnal range was negative. In addition, the four precipitation variables had comparable effects on FD (Figure 6). The model also indicated a positive effect of lake area (standardized path coefficient is 0.21 , Figure 6).

\section{Relationship between waterbirds functional diversity and lake productivity}

The final integrated SEM combined lake productivity and waterbirds FD together and included an explicit pathway from productivity to waterbirds FD (Figure 7). The model had reasonably adequate explanation power for the three key latent variables $\left(R^{2}\right.$ for climate, waterbirds FD and lake productivity was 0.73 , 0.56 and 0.96 , respectively. Figure 7). From the fitted path coefficients, climate had the greatest effect on waterbirds FD (0.65), which were similar to that of the waterbirds FD model (Figure 6). The effects of geographic position (0.60) was relatively strong, while the effects of other variables, including lake morphology $(0.21)$, lake productivity $(0.17)$ and nutrient $(0.16$, indirectly via its effect on lake productivity) were relatively weak. 


\section{Discussion}

In this study, we applied integrated modelling procedures (SEM) to productivity and waterbirds functional diversity data collected from lakes and reservoirs in the arid and semi-arid northern China covering over 5 million $\mathrm{km}^{2}$ with the aim to explore macroecological pattern involving geographic gradients in inland aquatic systems. Both lake productivity and waterbirds FD displayed strong geographical variations across northern China (Figure 3). We found that the geographic position exerted effects on lake productivity and waterbirds FD in a similar way, i.e. through its influences on climatic conditions, which was defined by seven bioclimatic variables in this study. This causality from geographic position to climatic conditions was significant and consistent in all three SEMs. Specifically, our analyses showed an unambiguous decreasing elevational gradient for both lake productivity and waterbirds FD (Herzog, Kessler, \& Bach, 2005; Rahbek, 1995). An increasing gradient with location coordinates was also obvious; and the effects of latitude (through its effects on climate) on both lake productivity and waterbirds FD were relatively weaker than those of longitude. Moreover, the "latitudinal gradient", which predicts species diversity decreases when moving away from the equator towards northern latitudes (Jetz, Thomas, Joy, Hartmann, \& Mooers, 2012), was not supported. Instead, we found evidence of a reverse trend in our analyses (Figure 4a). The opposite latitudinal gradient in this study should be treated with cautions as the study focused on the temperate zone that have a rather narrow latitudinal range and strong negative effects of elevation might obscure the real latitudinal pattern. Nevertheless, our analysis results supported a number of hypotheses underlying the geographic gradients by Field et al. (2009): 1) Climate; 2) Productivity; and 3) Size of ecosystem. More importantly, our results revealed a hierarchical structure of drivers that regulate the observed biodiversity and productivity patterns (Macneil et al., 2009).

\section{Drivers of geographic and elevational patterns of lake productivity}

The lake productivity model had relatively high performance in explaining the observed geographic and elevational gradients ( $R^{2}$ for separated and integrated models was 0.93 and 0.96 , respectively, Figure 5 and 7). Both linear regression analysis (Figure 4d, 4e) and structural equation modeling (Figure 5 and 7 ) showed that lake productivity was positively related with water TN and TP concentration. Moreover, the results from the integrated SEM indicated that the effect of nutrient, which was defined by TN and TP concentrations in water, was much stronger than that of climate. The close relationship between nutrient, lake chlorophyll a concentration, and lake productivity (Jeppesen et al., 2005; Smith, 1979) was expected because nitrogen and phosphorus are important limiting nutrients in freshwater ecosystems (Elser et al., 2007; Schindler, 1974). Lake ecosystem productivity depends on the supply of nutrients, especially phosphorus (Wetzel, 2001). According to previous studies, phosphorus loading alone could explain 79-95\% of the variances in lake chlorophyll $a$ concentration (Schindler, 1978).

Climatic conditions, measured mainly by temperature and precipitation variables including mean temperature of the wettest quarter, mean temperature of the warmest quarter, annual total precipitation, precipitation of driest month, and precipitation of the warmest quarter also had positive effects on lake productivity, except for mean diurnal range which showed the opposite trend (Figure 5 and 7 ). Climatic variation has been found to influence the magnitude of chlorophylla concentration (O'Reilly, Alin, Plisnier, Cohen, \& Mckee, 2003). Lake productivity increased with air temperature, which is the function of solar energy input. (Warner \& Lesht, 2015) reported that air temperature and precipitation were identified as important predictors, which had positive effects on chlorophyll $a$. Our results are consistent with those studies, although the mechanisms are not clear. One possibility is that higher air temperature reduces ice cover, which facilitates wind-induced mixing and nutrient resuspension (Nicholls, 1998; Schwab, Eadie, Assel, \& Roebber, 2009). And increases in the form of rain would cause increased run-off, which could bring more nutrients to the lakes from non-monitored or diffuse non-point sources. However, these hypotheses were not fully explored in our study, and further researches are needed to understand the mechanisms on how climate influences lake productivity. In addition, in our study, it was mean diurnal range, mean temperature of the wettest quarter, mean temperature of the warmest quarter showed significant effects on lake productivity. For which, it may due to the sampling time (i.e. we monitored lake chl- $\alpha$ in summer). 


\section{Drivers of geographic and elevational patterns of waterbirds functional diversity}

The waterbirds FD SEMs achieved sufficient performance in explaining the spatial variations in waterbirds FD ( $R^{2}$ for both separated and integrated models were 0.52 and 0.56 respectively, Figure 6 and 7 ). Geographic position, defined by latitude, longitude and altitude, had dominating effect on waterbirds FD through its influence on climate. Climate is typically a strong descriptor of broad-scale richness patterns (Hawkins et al., 2003), and the theory that climate's control of energy drives the global richness gradient has generated an extensive literature quantifying the relationship between species richness and climatic variables (Whittaker et al., 2007). Our results demonstrated that waterbirds FD increased with temperature, giving empirical affirmation to the species-energy hypothesis in that species diversity increases with environmental temperature (Allen, Brown, \& Gillooly, 2002). Temperature is one of major determinants of latitudinal and altitudinal gradients in animal diversity (Allen et al., 2002; Rohde, 1992), which may be explained by energy hypothesis, although the underlying mechanism remains unknown (Hawkins et al., 2003). The model results also showed that waterbirds FD increased significantly with precipitation. Furthermore, the modelled path coefficients indicated that precipitation was more important than that of temperature in our system. Precipitation is one of the resource-based estimates of available energy, especially in arid and semi-arid ecosystems (Brown \& Davidson, 1977), where biodiversity patterns are strongly related to precipitation amount (Waide et al., 1999). This is particularly true for waterbirds, whose distribution is generally determined by rainfall (Wen et al., 2016) through changing habitat availability, like water depth, habitat area and habitat diversity (Canepuccia, Isacch, Gagliardini, Escalante, \& Iribarne, 2007). As most of the lakes included in our study are located in the arid and semi-arid region of China, precipitation is critical to maintain enough habitat area for waterbirds.

Lake morphology, which was defined solely by lake area in this study, had positive effect on waterbirds FD. This pattern resembles the common species-area relationship observed in many ecosystems (Arrhenius, 1921; Guadagnin, Maltchik, \& Fonseca, 2009; Keil, Storch, \& Jetz, 2015; MacArthur \& Wilson, 1967; Nogues-Bravo \& Araujo, 2006; Rosenzweig, 1995). According to the theory of island biogeography (MacArthur \& Wilson, 1967), large and more diverse ecosystems are likely to harbor more species due to higher immigration rates and lower extinction rates. Indeed, lakes in arid and semi-arid zones can be regarded as aquatic islands in a terrestrial world, offering an explanation for the positive species-area relation in our analysis. This finding is consistent with Suter (Suter, 1994), who reported species-area relationship for waterfowl assemblages on the 20 major Swiss lakes north of the Alps. Likewise, Froneman et al. (2001) described a positive speciesarea relationship in waterbirds communities in farm ponds, South Africa, and Guadagnin et al. (2009) also described that the number of waterbirds species in wetlands from the Atlantic coastal zone of Brazil showed a positive relationship with their size.

\section{Relationship between waterbirds species richness and lake productivity}

Many studies revealed that productivity affects diversity (Carpenter et al., 1987; Dodson et al., 2000; Mittelbach et al., 2001), especially for plants (Chase \& Leibold, 2002). Nonetheless, no general consensus concerning the form of the pattern has emerged based on theoretical considerations or empirical findings (Waide et al., 1999). And positive, negative, and hump-shaped patterns were common at most spatial scales and no one pattern predominated (Mittelbach et al., 2001). For avian species, particularly waterbirds, there are only a few studies presented the relationship between diversity and productivity (Hawkins et al., 2003; Hurlbert \& Allen, 2004). Results of our integrated SEM gave evidence to support the causality from lake productivity to waterbirds FD albeit the relationship was weak in comparison to other factors. As the majority of waterbirds forage on the riparian zone of lakes (mean trait value of foraging at ground was greater than $55 \%$ for all lakes, Appendix A1) and have plants as their major diets (Appendix A2), this weak causality is expected. 


\section{Conclusions and caveats}

A major contribution of this study is that our findings reveal the key environmental drivers of large-scale patterns in lake productivity and functional diversity using advanced statistical techniques (i.e. SEM). This approach showed that the observed geographical and altitudinal gradients in lake productivity and waterbirds FD (Figure 3) can be partly explicated by the gradients in climatic conditions, which is in term significantly related to the geographic position of the lakes on the earth surface. As the relationship between productivity and species diversity in arid and semi-arid ecosystems has not been addressed, our study could contribute to the mechanistic explanations underlying the observed broad - scale biodiversity gradients in arid and semi-arid region. However, site-specific factors, such as lake morphology (for waterbirds) and nutrients (for productivity) impose their effects independently (Figure 5-7), and their effects could be more important than climatic variables (e.g. for lake productivity). These results, although supporting some primary macroecological biodiversity theories such as species-energy and species-resource hypothesis, could not lead to a mechanism that unifies these theories (Mcgill, 2010), exemplifying one key limitation of statistical analyses: statistical relationships do not necessarily reveal the underlying mechanisms regulating waterbirds biodiversity (Stomp et al., 2011). For example, the SEM indicates that altitude has a strong negative effect (indirectly through climate and lake productivity, Figure 7) on waterbirds FD. However, these causal paths could be driven by other environmental variables that co-vary with altitude but were not measured in our study. For instance, seasonal variation in environmental conditions increases at higher elevation, which could reduce species diversity by excluding sensitive species with a narrow tolerance range (Currie et al., 2004). Nevertheless, through articulating the dominant processes, our results could contribute to future studies seeking mechanistic explanations underlying the observed macroecological phenomena.

\section{Acknowledgements}

The research was supported by the Special Foundation for Basic Scientific and Technological Research Program (2013FY111800). We gratefully appreciate the help provided by the Administration of Wuliangushai Nature Reserve, the Administration of Wulagai Nature Reserve, the Administration of Khorchin Nature Reserve, the Administration of Dalinor Nature Reserve, the Administration of Chaganhu Nature Reserve, the Administration of Hengshuihu Nature Reserve and the Administration of Shahu Nature Reserve to access the study sites and provide facilitiesfor the surveys. Our thanks are especially to Dr. Wang Yuyu, Dr. Jiao Shengwu, Mr. Mo Xunqiang, Liu Yunzhu, Tao Cui, Chen Zhengrong, Qu Shang, Li Xiaojing, Tong Yuping, Li Yiyi, Zhu Yi, Yang Lingfan, Sun Gongqi, Li Gang and Jeroen Saccheri for assistance during the fieldwork; and to Li Yiyi for laboratory assistance and Li yu for assistance in part of data collection.

\section{Conflict of Interest}

None declared.

\section{Authors' Contributions}

LGC provided funds, LGC, WL and ZYM originally formulated the idea, WL and ZYM developed methodology, ZYM, TWZ, ZQ, THT and JYF conducted fieldwork and data collection, WL and ZYM performed statistical analyses, ZYM wrote the first version of the manuscript, WL and LGC revised the manuscript. All authors contributed to the final version of the manuscript.

\section{Data Availability Statement}

The data used in this study have been archived through Dryad online data repository and are publically available at https://doi.org/10.5061/dryad.mpg4f4qwd.

\section{References}

Allen, A. P., Brown, J. H., \& Gillooly, J. F. (2002). Global Biodiversity, Biochemical Kinetics, and the Energetic-Equivalence Rule.Science, 297 (5586), 1545-1548. doi:10.1126/science.1072380 
Arrhenius, O. (1921). Species and Area. Journal of Ecology, 9 (1), 95-99. doi:10.2307/2255763

Astorga, A., Heino, J., Luoto, M., \& Muotka, T. (2011). Freshwater biodiversity at regional extent: determinants of macroinvertebrate taxonomic richness in headwater streams. Ecography, 34 (5), 705-713. doi:10.1111/j.1600-0587.2010.06427.x

Barbet-Massin, M., \& Jetz, W. (2015). The effect of range changes on the functional turnover, structure and diversity of bird assemblages under future climate scenarios. Global Change Biology, 21 (8), 2917-2928. doi:10.1111/gcb.12905

Barbour, C. D., \& Brown, J. H. (1974). Fish Species Diversity in Lakes. The American Naturalist, 108 (Volume 108, Number 962), 473-489. doi:10.1086/282927

Benedetti, Y., Morelli, F., Munafò, M., Assennato, F., Strollo, A., \& Santolini, R. (2020). Spatial associations among avian diversity, regulating and provisioning ecosystem services in Italy.Ecological Indicators, 108 , 105742. doi:10.1016/j.ecolind.2019.105742

Blendinger, P. G., \& Villegas, M. (2011). Crop size is more important than neighborhood fruit availability for fruit removal of Eugenia uniflora (Myrtaceae) by bird seed dispersers. Plant Ecology, 212 (5), 889-899. doi:10.1007/s11258-010-9873-Z

Bregman, T. P., Lees, A. C., MacGregor, H. E. A., Darski, B., de Moura, N. G., Aleixo, A., . . Tobias, J. A. (2016). Using avian functional traits to assess the impact of land-cover change on ecosystem processes linked to resilience in tropical forests. Proc Biol Sci, 283 (1844), 20161289. doi:10.1098/rspb.2016.1289

Brown, J. H., \& Davidson, D. W. (1977). Competition Between Seed-Eating Rodents and Ants in Desert Ecosystems. Science, 196 (4292), 880. doi:10.1126/science.196.4292.880

Canepuccia, A. D., Isacch, J. P., Gagliardini, D. A., Escalante, A. H., \& Iribarne, O. O. (2007). Waterbird Response to Changes in Habitat Area and Diversity Generated by Rainfall in a SW Atlantic Coastal Lagoon. Waterbirds the International Journal of Waterbird Biology, 30 (4), 541-553. doi:10.1675/15244695(2007)030[0541:wrtcih]2.0.co;2

Caro, T. M., \& O'Doherty, G. (1999). On the Use of Surrogate Species in Conservation Biology. Conservation Biology, 13 (4), 805-814. doi:10.1046/j.1523-1739.1999.98338.x

Carpenter, S. R., Kitchell, J. F., Hodgson, J. R., Cochran, P. A., Elser, J. J., Elser, M. M., . . Ende, C. N. V. (1987). Regulation of Lake Primary Productivity by Food Web Structure. Ecology, 68 (6), 1863-1876. doi:10.2307/1939878

Castro-Insua, A., Gomez-Rodriguez, C., \& Baselga, A. (2016). Break the pattern: breakpoints in beta diversity of vertebrates are general across clades and suggest common historical causes. Global Ecology $\mathcal{E}^{3}$ Biogeography, 25 (11), 1279-1283. doi:10.1111/geb.12507

Chapman, P. M., Tobias, J. A., Edwards, D. P., Davies, R. G., \& Vamosi, S. (2018). Contrasting impacts of land-use change on phylogenetic and functional diversity of tropical forest birds. Journal of Applied Ecology, 55 (4), 1604-1614. doi:10.1111/1365-2664.13073

Chase, J. M., \& Leibold, M. A. (2002). Spatial scale dictates the productivity-biodiversity relationship. Nature, 416 (6879), 427-430. doi:10.1038/416427a

Cintra, R. (2015). Spatial distribution and composition of waterbirds in relation to limnological conditions in the Amazon basin.Hydrobiologia, 747 (1), 1-18. doi:10.1007/s10750-014-2148-2

Currie, D. J., Mittelbach, G. G., Cornell, H. V., Field, R., Guegan, J. F., Hawkins, B. A., . . . O'Brien, E. (2004). Predictions and tests of climate-based hypotheses of broad-scale variation in taxonomic richness.Ecology Letters, 7 (12), 1121-1134. doi:10.1111/j.1461-0248.2004.00671.x 
Currie, D. J., \& Paquin, V. (1987). Large-scale biogeographical patterns of species richness of trees. Nature, 329 (6137), 326-327. doi:10.1038/329326a0

Devictor, V., Mouillot, D., Meynard, C., Jiguet, F., Thuiller, W., \& Mouquet, N. (2010). Spatial mismatch and congruence between taxonomic, phylogenetic and functional diversity: the need for integrative conservation strategies in a changing world. Ecology Letters, 13 (8), 1030-1040. doi:10.1111/j.1461-0248.2010.01493.x

Diaz, S., \& Cabido, M. (2001). Vive la différence: plant functional diversity matters to ecosystem processes. Trends in Ecology $\& 3$ Evolution, 16 (11), 646-655. doi:10.1016/S0169-5347(01)02283-2

Dodson, S. I. (2008). Biodiversity in southern Wisconsin storm-water retention ponds: Correlations with watershed cover and productivity.Lake and Reservoir Management, 24 (4), 370-380. doi:10.1080/07438140809354847

Dodson, S. I., Arnott, S. E., \& Cottingham, K. L. (2000). The Relationship in Lake Communities between Primary Productivity and Species Richness. Ecology, 81 (10), 2662-2679. doi:10.2307/177332

Dudgeon, D., Arthington, A. H., Gessner, M. O., Kawabata, Z., Knowler, D. J., Lévêque, C., . . . Stiassny, M. L. (2006). Freshwater biodiversity: importance, threats, status and conservation challenges.Biological Reviews of the Cambridge Philosophical Society, 81 (2), 163-182. doi:10.1017/S1464793105006950

Elser, J. J., Bracken, M. E. S., Cleland, E. E., Gruner, D. S., Harpole, W. S., Hillebrand, H., . . Smith, J. E. (2007). Global analysis of nitrogen and phosphorus limitation of primary producers in freshwater, marine and terrestrial ecosystems. Ecology Letters, 10 (12), 1135-1142. doi:10.1111/j.1461-0248.2007.01113.x

Eppley, R., Stewart, E., Abbott, M. R., \& Heyman, U. (1985). Estimating ocean primary production from satellite chlorophyll. Introduction to regional differences and statistics for the Southern California Bight. Journal of Plankton Research, 7 (1), 57-70. doi:10.1093/plankt/7.1.57

Falkowski, P. G., \& Raven, J. A. (2013). Aquatic photosynthesis : Princeton University Press.

Field, R., Hawkins, B. A., Cornell, H. V., Currie, D. J., Diniz-Filho, J. A. F., Kaufman, D. M., . . . Thierry, O. (2009). Spatial species-richness gradients across scales: a meta-analysis. Journal of Biogeography, 36 (1), $132-147$.

Flynn, D. F. B., Gogol-Prokurat, M., Nogeire, T., Molinari, N., Richers, B. T., Lin, B. B., . . . DeClerck, F. (2009). Loss of functional diversity under land use intensification across multiple taxa.Ecology Letters, 12 (1), 22-33. doi:10.1111/j.1461-0248.2008.01255.x

Flynn, D. F. B., Mirotchnick, N., Jain, M., Palmer, M. I., \& Naeem, S. (2011). Functional and phylogenetic diversity as predictors of biodiversity - ecosystem-function relationships. Ecology, 92 (8), 1573-1581. doi:10.1890/10-1245.1

Fox, J., Weisberg, S., Adler, D., Bates, D., Baud-Bovy, G., Ellison, S., . . . Heiberger, R. (2012). Package 'car'. Vienna: R Foundation for Statistical Computing.

Frund, J., Dormann, C. F., Holzschuh, A., \& Tscharntke, T. (2013). Bee diversity effects on pollination depend on functional complementarity and niche shifts. Ecology, 94 (9), 2042-2054. doi:10.1890/12-1620.1

Froneman, A., Mangnall, M. J., Little, R. M., \& Crowe, T. M. (2001). Waterbird assemblages and associated habitat characteristics of farm ponds in the Western Cape, South Africa. Biodiversity \& Conservation, 10 (2), 251-270. doi:10.1023/a:1008904421948

Fu, C., Wu, J., Wang, X., Lei, G., \& Chen, J. (2004). Patterns of diversity, altitudinal range and body size among freshwater fishes in the Yangtze River basin, China. Global Ecology 83 Biogeography, 13 (6), 543-552. doi:10.1111/j.1466-822X.2004.00122.x

Gaston, K. J. (2000). Global patterns in biodiversity. Nature, 405 (6783), 220-227. doi:10.1038/35012228 
Gong, D. Y., Shi, P. J., \& Wang, J. A. (2004). Daily precipitation changes in the semi-arid region over northern China. Journal of Arid Environments, 59 (4), 771-784. doi:10.1016/j.jaridenv.2004.02.006

Grace, J. B. (2006). Structural equation modeling and natural systems . New York: Cambridge University Press.

Grace, J. B., \& Bollen, K. A. (2005). Interpreting the Results from Multiple Regression and Structural Equation Models. Bulletin of the Ecological Society of America, 86 (4), 283-295. doi:10.1890/00129623(2005)86[283:ITRFMR]2.0.CO;2

Grace, J. B., Schoolmaster, D. R., Guntenspergen, G. R., Little, A. M., Mitchell, B. R., Miller, K. M., \& Schweiger, E. W. (2012). Guidelines for a graph-theoretic implementation of structural equation modeling.Ecosphere, 3 (8), 73. doi:10.1890/ES12-00048.1

Grime, J. P. (1973). Competitive Exclusion In Herbaceous Vegetation.Nature, 242 , 344-347. doi:10.1038/242344a0

Guadagnin, D. L., Maltchik, L., \& Fonseca, C. R. (2009). Species-area relationship of Neotropical waterbird assemblages in remnant wetlands: looking at the mechanisms. Diversity \& Distributions, 15 (2), 319-327. doi:10.1111/j.1472-4642.2008.00533.x

Hawkins, B. A. (2001). Ecology's oldest pattern? Trends in Ecology ES Evolution, 16 (8), 470. doi:10.1016/S0160-9327(00)01369-7

Hawkins, B. A., Field, R., Cornell, H. V., Currie, D. J., Guegan, J. F., Kaufman, D. M., . . . Porter, E. E. (2003). Energy, water, and broad-scale geographic patterns of species richness. Ecology, 84 (12), 3105-3117. doi:10.1890/03-8006

Heino, J. (2002). Concordance of species richness patterns among multiple freshwater taxa: a regional perspective. Biodiversity and Conservation, 11 (1), 137-147. doi:10.1023/a:1014075901605

Heino, J. (2011). A macroecological perspective of diversity patterns in the freshwater realm. Freshwater Biology, 56 (9), 1703-1722. doi:10.1111/j.1365-2427.2011.02610.x

Herzog, S. K., Kessler, M., \& Bach, K. (2005). The elevational gradient in Andean bird species richness at the local scale: a foothill peak and a high-elevation plateau. Ecography, 28 (2), 209-222. doi:10.1111/j.09067590.2005.03935.x

Hooper, D. U., Chapin III, F. S., Ewel, J. J., Hector, A., Inchausti, P., Lavorel, S., . . . Wardle, D. A. (2005). Effects of biodiversity on ecosystem functioning: a consensus of current knowledge.Ecological Monographs, 75 (1), 3-35. doi:10.1890/04-0922

Hu, L. t., \& Bentler, P. M. (1999). Cutoff criteria for fit indexes in covariance structure analysis: Conventional criteria versus new alternatives. Structural Equation Modeling: A Multidisciplinary Journal, 6 (1), 1-55. doi:10.1080/10705519909540118

Hurlbert, \& Allen, H. (2004). Species-energy relationship and habitat complexity in bird communities. Ecology Letters, 7 (8), 714-720. doi:10.1111/j.1461-0248.2004.00630.x

Irz, P., Argillier, C., \& Thierry, O. (2004). Native and introduced fish species richness in French lakes: local and regional influences. Global Ecology \& Biogeography, 13 (4), 335-344. doi:10.1111/j.1466822X.2004.00109.x

Jacobsen, D. (2004). Contrasting patterns in local and zonal family richness of stream invertebrates along an Andean altitudinal gradient.Freshwater Biology, 49 (10), 1293-1305. doi:10.1111/j.1365-2427.2004.01274.x

Jeppesen, E., Sondergaard, M., Jensen, J. P., Havens, K. E., Anneville, O., Carvalho, L., . . . Foy, B. (2005). Lake responses to reduced nutrient loading - an analysis of contemporary long-term data from 35 case studies. Freshwater Biology, 50 (10), 1747-1771. doi:10.1111/j.1365-2427.2005.01415.x 
Jetz, W., Thomas, G. H., Joy, J. B., Hartmann, K., \& Mooers, A. O. (2012). The global diversity of birds in space and time. Nature, 491 (7424), 444-448. doi:10.1038/nature11631

Keil, P., Storch, D., \& Jetz, W. (2015). On the decline of biodiversity due to area loss. Nature Communications, 6 , 8837. doi:10.1038/ncomms 9837

Kissling, W. D., Sekercioglu, C. H., \& Jetz, W. (2012). Bird dietary guild richness across latitudes, environments and biogeographic regions. Global Ecology and Biogeography, 21 (3/4), 328-340. doi:10.1111/j.14668238.2011.00679.x

Luck, G. W., Andrew, C., Lisa, S., \& Davies, Z. G. (2013). Changes in Bird Functional Diversity across Multiple Land Uses: Interpretations of Functional Redundancy Depend on Functional Group Identity. PLoS One, 8 (5), e63671-. doi:0.1371/journal.pone.0063671

MacArthur, R. H., \& Wilson, E. O. (1967). The theory of island biogeography . Princeton: Princeton University Press.

Macneil, M. A., Graham, N. A., Polunin, N. V., Kulbicki, M., Galzin, R., Harmelin-Vivien, M., \& Rushton, S. P. (2009). Hierarchical drivers of reef-fish metacommunity structure. Ecology, 90 (1), 252-264. doi:10.1890/07-0487.1

Mcgill, B. J. (2010). Towards a unification of unified theories of biodiversity. Ecology Letters, 13 (5), 627-642. doi:10.1111/j.1461-0248.2010.01449.x

Millennium Ecosystem Assessment. (2005). Ecosystems and Human Well-being: Synthesis . Washington (DC): Island Press.

Mittelbach, G. G., Steiner, C. F., Scheiner, S. M., Gross, K. L., Reynolds, H. L., Waide, R. B., . . . Gough, L. (2001). What Is the Observed Relationship between Species Richness and Productivity?Ecology, 82 (9), 2381-2396. doi:10.2307/2679922

Mouchet, M., Levers, C., Zupan, L., Kuemmerle, T., Plutzar, C., Erb, K., . . . Haberl, H. (2015). Testing the Effectiveness of Environmental Variables to Explain European Terrestrial Vertebrate Species Richness across Biogeographical Scales. PLoS One, 10 (7), e0131924. doi:10.1371/journal.pone.0131924

Naiman, R. J., \& Dudgeon, D. (2011). Global alteration of freshwaters: influences on human and environmental well-being. Ecological Research, 26 (5), 865-873.

Nicholls, K. H. (1998). El Nino, ice cover, and Great Lakes phosphorus: Implications for climate warming. Limnology \& Oceanography, 43 (4), 715-719. doi:10.4319/lo.1998.43.4.0715

Nogues-Bravo, D., \& Araujo, M. B. (2006). Species richness, area and climate correlates. Global Ecology \& Biogeography, 15 (5), 452-460. doi:10.1111/j.1466-822x.2006.00240.x

O'Reilly, C. M., Alin, S. R., Plisnier, P. D., Cohen, A. S., \& Mckee, B. A. (2003). Climate change decreases aquatic ecosystem productivity of Lake Tanganyika, Africa. Nature, 424 (6950), 766. doi:10.1038/nature01833

Petchey, O. L., Evans, K. L., Fishburn, I. S., \& Gaston, K. J. (2007). Low functional diversity and no redundancy in British avian assemblages. Journal of Animal Ecology, 76 (5), 977-985. doi:10.1111/j.13652656.2007.01271.x

Petchey, O. L., \& Gaston, K. J. (2006). Functional diversity: back to basics and looking forward. Ecology Letters, 9 (6), 741-758. doi:10.1111/j.1461-0248.2006.00924.x

Petchey, O. L., \& Gaston, K. J. (2007). Dendrograms and Measuring Functional Diversity. Oikos, 116 (8), 1422-1426. doi:10.1111/j.0030-1299.2007.15894.x 
Prescott, G. W., Gilroy, J. J., Haugaasen, T., Uribe, C. A. M., Foster, W. A., \& Edwards, D. P. (2016). Reducing the impacts of Neotropical oil palm development on functional diversity. Biological Conservation, 197 , 139-145. doi:10.1016/j.biocon.2016.02.013

Qian, H., Ricklefs, R. E., \& White, P. S. (2005). Beta diversity of angiosperms in temperate floras of eastern Asia and eastern North America. Ecology Letters, 8 (1), 15-22. doi:10.1111/j.1461-0248.2004.00682.x

R Development Core Team. (2019). R: A Language and Environment for Statistical Computing . Vienna: $\mathrm{R}$ Foundation for Statistical Computing.

Rahbek, C. (1995). The elevational gradient of species richness: a uniform pattern? Ecography, 18 (2), 200-205. doi:10.1111/j.1600-0587.1995.tb00341.x

Rohde, K. (1992). Latitudinal gradients in species diversity: the search for the primary cause. Oikos, 65 (3), 514-527. doi:10.2307/3545569

Rosenzweig, M. L. (1995). Species diversity in space and time . Cambridge: Cambridge University Press.

Rosseel, Y., Oberski, D., Byrnes, J., Vanbrabant, L., Savalei, V., Merkle, E., . . . Rosseel, M. Y. (2015). Package 'Lavaan': Latent Variable Analysis . R Package.

Sala, O. E., Chapin, F. S., Armesto, J. J., Berlow, R., Dirzo, R., Huber-sanwald, E., . . . Wall, D. H. (2000). Global biodiversity scenarios for the year 2100. Science, 287, 1770-1774. doi:10.1126/science.287.5459.1770

Schindler, D. W. (1974). Eutrophication and Recovery in Experimental Lakes: Implications for Lake Management. Science, 184 (4139), 897-899. doi:10.1126/science.184.4139.897

Schindler, D. W. (1978). Factors regulating phytoplankton production and standing crop in the world's freshwaters. Limnology 83 Oceanography, 23 (3), 478-486. doi:10.4319/lo.1978.23.3.0478

Schwab, D. J., Eadie, B. J., Assel, R. A., \& Roebber, P. J. (2009). Climatology of Large Sediment Resuspension Events in Southern Lake Michigan. Journal of Great Lakes Research, 32 (1), 50-62. doi:10.3394/03801330(2006)32[50:colsre]2.0.co;2

Sekercioglu, C. H. (2006). Increasing awareness of avian ecological function. Trends in Ecology E Evolution, 21 (8), 464-471. doi:https://doi.org/10.1016/j.tree.2006.05.007

Shah, D. N., Domisch, S., Pauls, S. U., Haase, P., \& Jahnig, S. C. (2014). Current and future latitudinal gradients in stream macroinvertebrate richness across North America. Freshwater Science, 33 (4), 1136-1147. doi:10.1086/678492

Smith, V. H. (1979). Nutrient dependence of primary productivity in lakes. Limnology $\&$ Oceanography, 24 (6), 1051-1064. doi:10.4319/lo.1979.24.6.1051

Socolar, J. B., Gilroy, J. J., Kunin, W. E., \& Edwards, D. P. (2016). How Should BetaDiversity Inform Biodiversity Conservation? Trends in Ecology \& Evolution, 31 (1), 67-80. doi:https://doi.org/10.1016/j.tree.2015.11.005

Stein, A., Gerstner, K., \& Kreft, H. (2014). Environmental heterogeneity as a universal driver of species richness across taxa, biomes and spatial scales. Ecology Letters, 17 (7), 866. doi:10.1111/ele.12277

Stendera, S., Adrian, R., Bonada, N., Canedo-Arguelles, M., Hugueny, B., Januschke, K., . . . Hering, D. (2012). Drivers and stressors of freshwater biodiversity patterns across different ecosystems and scales: a review. Hydrobiologia, 696 (1), 1-28. doi:10.1007/s10750-012-1183-0

Stomp, M., Huisman, J., Mittelbach, G. G., Litchman, E., \& Klausmeier, C. A. (2011). Large-scale biodiversity patterns in freshwater phytoplankton. Ecology, 92 (11), 2096. doi:10.1890/10-1023.1

Storch, D., Davies, R. G., Zaji, S., d, x., ek, Orme, C. D. L., . . . Bennett, P. M. (2006). Energy, range dynamics and global species richness patterns: reconciling mid-domain effects and environmental 
determinants of avian diversity. Ecology Letters, 9 (12), 1308-1320. doi:10.1111/j.1461-0248.2006.00984.x

Suter, W. (1994). Overwintering waterfowl on Swiss lakes: how are abundance and species richness influenced by trophic status and lake morphology? Hydrobiologia, 279 (1), 1-14. doi:10.1007/bf00027836

Tisseuil, C., Cornu, J. F., Beauchard, O., Brosse, S., Darwall, W., Holland, R., . . . Oberdorff, T. (2013). Global diversity patterns and cross-taxa convergence in freshwater systems. Journal of Animal Ecology, 82 (2), 365-376. doi:10.1111/1365-2656.12018

Tittensor, D. P., Mora, C., Jetz, W., Lotze, H. K., Ricard, D., Berghe, E. V., \& Worm, B. (2010). Global patterns and predictors of marine biodiversity across taxa. Nature, 466 (7310), 1098-1101. doi:10.1038/nature09329

Villeger, S., Mason, N. W. H., \& Mouillot, D. (2008). New multidimensional functional diversity indices for a multifaceted framework in functional ecology. Ecology, 89 , 2290-2301. doi:10.1890/07-1206.1

Waide, R. B., Willig, M. R., Steiner, C. F., Mittelbach, G., Gough, L., Dodson, S. I., . . . Parmenter, R. (1999). The relationship between productivity and species richness. Annual Review of Ecology Evolution 83 Systematics, 30 , 257-300. doi:10.1146/annurev.ecolsys.30.1.257

Wang, S. M., \& Dou, H. S. (1998). Lakes in China . Beijing: Science Press.

Warner, D. M., \& Lesht, B. M. (2015). Relative importance of phosphorus, invasive mussels and climate for patterns in chlorophyll a and primary production in Lakes Michigan and Huron. Freshwater Biology, 60 (5), 1029-1043. doi:10.1111/fwb.12569

Wen, L., Saintilan, N., Reid, J. R. W., \& Colloff, M. J. (2016). Changes in distribution of waterbirds following prolonged drought reflect habitat availability in coastal and inland regions.Ecology $\&$ Evolution, 6 (18), 6672-6689. doi:10.1002/ece3.2091

Wetzel, R. G. (2001). Limnology. Third edition. San Diego, California: Academic Press.

Whittaker, R., Nogues-Bravo, D., \& Araujo, M. (2007). Geographical gradients of species richness: a test of the water-energy conjecture of Hawkins et al. (2003) using European data for five taxa. Global Ecology $\mathcal{B}^{3}$ Biogeography, 16 (1), 76-89. doi:10.1111/j.1466-8238.2006.00268.x

Williams, W. D. (1999). Salinisation: A major threat to water resources in the arid and semi-arid regions of the world. Lakes 85 Reservoirs Research 85 Management, 4 (3-4), 85-91.

Willig, M. R., Kaufman, D. M., \& Stevens, R. D. (2003). Latitudinal Gradients of Biodiversity: Pattern, Process, Scale, and Synthesis.Annual Review of Ecology Evolution 83 Systematics, 34 (2), 273-309. doi:10.1146/annurev.ecolsys.34.012103.144032

Wilman, H., Belmaker, J., Simpson, J., de la Rosa, C., Rivadeneira, M. M., \& Jetz, W. (2014). EltonTraits 1.0: Species-level foraging attributes of the world's birds and mammals. Ecology, 95 (7), 2027-2027. doi:10.1890/13-1917.1

Xia, S., Liu, Y., Wang, Y., Chen, B., Jia, Y., Liu, G., . . . Wen, L. (2016). Wintering waterbirds in a large river floodplain: Hydrological connectivity is the key for reconciling development and conservation.Science of The Total Environment, 573 , 645. doi:10.1016/j.scitotenv.2016.08.147

Zeng, Q., Reid, J., Saintilan, N., Colloff, M. J., Lei, G., \& Wen, L. (2019). Contrasting diversity patterns of breeding Anatidae in the Northern and Southern Hemispheres. Ecology and Evolution, 9 (17), 9990-10003. doi:10.1002/ece3.5540

Table 1 The five trait types and 16 specific traits used to characterize waterbirds functional diversity in lakes and reservoirs located in North China. 


\begin{tabular}{|c|c|c|c|c|}
\hline Type & Trait & Mean & $\mathrm{SD}$ & Sources \\
\hline \multirow[t]{6}{*}{ Resource Quantity } & Size $(\mathrm{cm})$ & 48.48 & 31.65 & $\mathrm{a}$ and $\mathrm{b}$ \\
\hline & $\operatorname{Mass}(\mathrm{g})$ & 1078.07 & 1912.80 & $\mathrm{a}$ and $\mathrm{b}$ \\
\hline & Wingspan $(\mathrm{cm})$ & 89.86 & 52.22 & $\mathrm{a}$ \\
\hline & Migration & - & - & $\mathrm{b}$ \\
\hline & Pelagic & - & - & $\mathrm{b}$ \\
\hline & $\begin{array}{l}\text { Breeding range } \\
\left(\mathrm{km}^{2}, \mathrm{log}\right. \\
\text { transformed })\end{array}$ & 7.24 & 0.71 & $\mathrm{~b}$ \\
\hline Life history & Generation (year) & 8.07 & 2.85 & $\mathrm{a}$ \\
\hline \multirow[t]{2}{*}{ Reproduction } & $\begin{array}{l}\text { Clutch size (no. of } \\
\text { eggs) }\end{array}$ & 4.55 & 2.17 & $\mathrm{a}$ and $\mathrm{b}$ \\
\hline & Incubation (day) & 24.89 & 4.63 & c \\
\hline \multirow[t]{4}{*}{ Diet } & $\begin{array}{l}\text { Diet-Inv (\% of } \\
\text { invertebrate) }\end{array}$ & 49.53 & 31.84 & c \\
\hline & $\begin{array}{l}\text { Diet-V (\% of } \\
\text { vertebrate) }\end{array}$ & 22.84 & 28.17 & c \\
\hline & $\begin{array}{l}\text { Diet-Scav ( } \% \text { of } \\
\text { scavenger) }\end{array}$ & 0.88 & 3.84 & c \\
\hline & $\begin{array}{l}\text { Diet-Plant (\% of } \\
\text { plant materials) }\end{array}$ & 26.76 & 31.97 & c \\
\hline \multirow[t]{3}{*}{ Habitat } & $\begin{array}{l}\text { Hab-W ( } \% \text { of time } \\
\text { on water surface) }\end{array}$ & 15.20 & 30.87 & c \\
\hline & $\begin{array}{l}\text { Hab-Rip ( } \% \text { of time } \\
\text { on riparian area) }\end{array}$ & 40.34 & 28.88 & c \\
\hline & $\begin{array}{l}\text { Hab-G ( } \% \text { of time } \\
\text { on ground) }\end{array}$ & 41.91 & 32.51 & c \\
\hline
\end{tabular}

1. Planet of Birds, website visited 23 Jun 2016:http://www.planetofbirds.com/

2. BirddLife International, website visited 28 Jun 2016:http://datazone.birdlife.org/

3. Wilman et al., 2014

Table 2 Multiple regression analysis of waterbirds functional diversity (dependent variable) as a function of environmental variables. Only significant variables were reported $(P<0.05)$.

\begin{tabular}{llllc}
\hline Regression variables & Partial regression coefficients & Standard error & Standardized coefficients & $p$ \\
\hline Constant & -1.246 & 0.246 & & $<$ \\
Lake area & 0.425 & 0.073 & 0.561 & $<$ \\
Mean temperature of wettest quarter & 0.050 & 0.035 & 1.128 & $<$ \\
Annual total precipitation & 0.065 & 0.019 & 1.739 & $<$ \\
Precipitation of the warmest quarter & -0.062 & 0.026 & -1.237 & $<$ \\
Model summary & $\mathrm{R}^{2}=0.710, P<0.001$ & $\mathrm{R}^{2}=0.710, P<0.001$ & $\mathrm{R}^{2}=0.710, P<0.001$ & $\mathrm{R}$ \\
\hline
\end{tabular}

Table 3 Multiple regression analysis of each environmental variables as function of geographical location. Only significant variables were reported $(P<0.05)$.

\begin{tabular}{ll}
\hline Variables & Partial regression coefficients \\
\hline Lake productivity $\left(\right.$ model $\left.\mathrm{R}^{2}=0.527, P<0.001\right)$ & Lake productivity $\left(\right.$ model $\left.\mathrm{R}^{2}=0.527, P<0.001\right)$ \\
Constant & 3.335
\end{tabular}




\begin{tabular}{|c|c|}
\hline Variables & Partial regression coefficients \\
\hline Altitude & -0.001 \\
\hline Iean diurnal range $\left(\right.$ model $\left.\mathrm{R}^{2}=0.983, P<0.001\right)$ & Mean diurnal range $\left(\right.$ model $\left.\mathrm{R}^{2}=0.983, P<0.001\right)$ \\
\hline Constant & 679.672 \\
\hline Latitude & 3.563 \\
\hline ongitude & .886 \\
\hline Altitude & -0.054 \\
\hline Mean temperature of the wettest quarter $\left(\right.$ model $\left.\mathrm{R}^{2}=0.985, P<0.001\right)$ & Mean temperature of the wettest quarter (model \\
\hline Constant & 555.232 \\
\hline Lati & -2.335 \\
\hline itude & -1.8 \\
\hline Altitude & -0.055 \\
\hline Mean temperature of the warmest quarter $\left(\right.$ model $\left.\mathrm{R}^{2}=0.989, P<0.001\right)$ & Mean temperature of the warmest quarter (model \\
\hline W & 614.684 \\
\hline Lat & -4.048 \\
\hline Lor & -1.628 \\
\hline Alti & -0.058 \\
\hline Annual total precipitation (model $\mathrm{R}^{2}=0.655, P<0.001$ ) & Annual total precipitation $\left(\right.$ model $\mathrm{R}^{2}=0.655, P$ \\
\hline 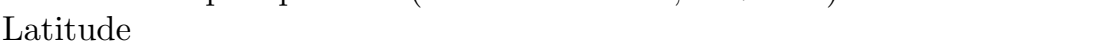 & -13.296 \\
\hline Lon & 12.088 \\
\hline Precipitation of the driest month (model $\mathrm{R}^{2}=0.508, P<0.001$ ) & Precipitation of the driest month (model $\mathrm{R}^{2}=0.5$ \\
\hline 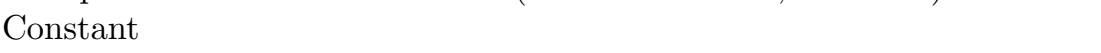 & -6.546 \\
\hline Long & 0.077 \\
\hline Precipitation of the warmest quarter (model $\mathrm{R}^{2}=0.508, P<0.001$ ) & Precipitation of the warmest quarter (model $\mathrm{R}^{2}=$ \\
\hline Constant & -398.625 \\
\hline Longitude & 8.540 \\
\hline Precipitation of the coldest quarter $\left(\right.$ model $\mathrm{R}^{2}=0.502, P<0.001$ ) & Precipitation of the coldest quarter $\left(\right.$ model $\mathrm{R}^{2}=$ \\
\hline Constant & -18.736 \\
\hline Longitude & 0.236 \\
\hline
\end{tabular}

Figure 1. A pair of Mute Swans (Cygnus olor) inhabits at Wuliangsuhai Lake, Inner Mongolia

Figure 2. Locations of the 35 surveyed lakes and reservoirs in North China. Elevation gradient is used as background

Figure 3. Map of the 35 surveyed lakes and reservoirs in North China showing (a) waterbirds species richness, (b) functional richness, and (c) lake productivity (mg.m- ${ }^{3}$ )

Figure 4. Patterns of species richness and lake productivity with environmental variables. Species richness of waterbirds as a function of (a) latitude, (b) longitude, and (c) altitude. Lake productivity (measured as chlorophyll $a$ ) as a function of (d) total nitrogen, (e) total phosphorus Data points correspond to individual lakes. Regression lines show best liner fits. All regression lines are significant $(P<0.05)$

Figure 5. SEM for lake productivity. Latent variables are in ovals and measured variables in rectangles. The strength of the causality (standardized path coefficient) is indicted by the width of the line. Black lines indicate positive effects while red lines mean negative impacts. T1: mean diurnal range, T2: mean temperature of the wettest quarter, T3: mean temperature of the warmest quarter, P1: annual total precipitation, P2: precipitation of the driest month, P3: precipitation of the warmest quarter, and P4: precipitation of the coldest quarter

Figure 6. SEM model for waterbirds functional diversity. Latent variables in ovals and measured variables 
in rectangles. The strength of the causality (standardized path coefficient for direct comparison) was indicted by the width of the link. Black lines indicate positive effects while red lines mean negative impacts. T1: mean diurnal range, T2: mean temperature of the wettest quarter, T3: mean temperature of the warmest quarter, P1: annual total precipitation, P2: precipitation of the driest month, P3: precipitation of the warmest quarter, and $\mathrm{P} 4$ : precipitation of the coldest quarter

Figure 7. Integrated SEM model in which waterbirds functional diversity is linked with lake productivity. Latent variables are in ovals and measured variables in rectangles. The strength of the causality (standardized path coefficient) was indicted by the width of the link. Black lines indicate positive effects while red lines mean negative impacts. T1: mean diurnal range, T2: mean temperature of the wettest quarter, T3: mean temperature of the warmest quarter, $\mathrm{P} 1$ : annual total precipitation, $\mathrm{P} 2$ : precipitation of the driest month, P3: precipitation of the warmest quarter, and P4: precipitation of the coldest quarter

\section{Appendices}

Appendix S1 Biometric trait data of for all 148 waterbird species recorded in this study.

\begin{tabular}{|c|c|c|c|c|c|c|c|c|c|}
\hline Waterbirds & Generation & Clutch & Incubation & Migratory & Size & Mass & DietV & DietInv & Diet \\
\hline Actitis_hypoleucos & 6.8 & 4 & 21.5 & $\mathrm{~A}$ & 20 & 48 & 40 & 50 & 0 \\
\hline Aix_galericulata & 7.4 & 10.4 & 30.5 & $\mathrm{~A}$ & 46 & 567.04 & 10 & 20 & 0 \\
\hline Amaurornis_phoenicurus & 3.7 & 6 & 20 & $\mathrm{~A}$ & 30.5 & 180 & 20 & 40 & 0 \\
\hline Anas_acuta & 6.8 & 7.9 & 23 & $\mathrm{~A}$ & 58 & 944.62 & 10 & 20 & 0 \\
\hline Anas_clypeata & 6.5 & 9.9 & 22 & A & 49.5 & 612.56 & 0 & 60 & 0 \\
\hline Anas_crecca & 6.3 & 9.4 & 22 & A & 36 & 341.89 & 0 & 30 & 0 \\
\hline Anas_falcata & 6.6 & 7.3 & 25 & $\mathrm{~A}$ & 46 & 645.83 & 0 & 10 & 0 \\
\hline Anas_formosa & 6.6 & 7.3 & 24.5 & A & 41 & 433.98 & 0 & 10 & 0 \\
\hline Anas_penelope & 6.4 & 8.5 & 24.5 & $\mathrm{~A}$ & 48 & 770.03 & 0 & 0 & 0 \\
\hline Anas_platyrhynchos & 6.6 & 10.8 & 27 & $\mathrm{~A}$ & 58.75 & 843.42 & 20 & 40 & 0 \\
\hline Anas_poecilorhyncha & 6.6 & 7.9 & 26 & $\mathrm{~A}$ & 60.5 & 999.96 & 0 & 10 & 0 \\
\hline Anas_querquedula & 6.5 & 8.5 & 22 & $\mathrm{~A}$ & 39 & 325.6 & 20 & 40 & 0 \\
\hline Anas_strepera & 6.6 & 9.8 & 24 & $\mathrm{~A}$ & 46 & 915.58 & 0 & 0 & 0 \\
\hline Anser_albifrons & 11.3 & 5.5 & 25 & $\mathrm{~A}$ & 75.5 & 2506.39 & 0 & 0 & 0 \\
\hline Anser_anser & 11.6 & 4.9 & 27.5 & $\mathrm{~A}$ & 82.5 & 3302.41 & 0 & 0 & 0 \\
\hline Anser_cygnoides & 11.4 & 5.5 & 28 & $\mathrm{~A}$ & 87 & 3511.94 & 0 & 0 & 0 \\
\hline Anser_erythropus & 11.4 & 4.9 & 26.5 & $\mathrm{~A}$ & 59.5 & 1755.5 & 0 & 0 & 0 \\
\hline Anser_fabalis & 11.4 & 4.9 & 27 & $\mathrm{~A}$ & 77.5 & 2754.73 & 0 & 0 & 0 \\
\hline Anser_indicus & 11.4 & 4.9 & 28.5 & $\mathrm{~A}$ & 73.5 & 2212.55 & 0 & 0 & 0 \\
\hline Ardea_cinerea & 10.3 & 3.9 & 25.5 & $\mathrm{~A}$ & 94 & 1443 & 80 & 20 & 0 \\
\hline Ardea_purpurea & 10.5 & 4 & 27.5 & $\mathrm{~A}$ & 84 & 1064.48 & 70 & 30 & 0 \\
\hline Ardeola_bacchus & 6.7 & 4 & 20 & $\mathrm{~A}$ & 47 & 304.89 & 30 & 70 & 0 \\
\hline Arenaria_interpres & 7.3 & 4 & 23 & $\mathrm{~A}$ & 23.5 & 135.98 & 0 & 80 & 0 \\
\hline Aythya_baeri & 7.6 & 7.7 & 27 & $\mathrm{~A}$ & 44 & 681.23 & 20 & 20 & 0 \\
\hline Aythya_ferina & 7.6 & 8.9 & 52.5 & $\mathrm{~A}$ & 45.5 & 822.99 & 20 & 10 & 0 \\
\hline Aythya_fuligula & 7.3 & 9.4 & 25.5 & $\mathrm{~A}$ & 43.5 & 701.17 & 0 & 50 & 10 \\
\hline Aythya_marila & 8.2 & 9.4 & 27 & $\mathrm{~A}$ & 45.5 & 1005.37 & 0 & 80 & 0 \\
\hline Aythya_nyroca & 7.6 & 8.9 & 26.5 & $\mathrm{~A}$ & 40 & 574 & 20 & 10 & 0 \\
\hline Botaurus_stellaris & 5.5 & 4.6 & 25.5 & $\mathrm{~A}$ & 72 & 1319.45 & 90 & 10 & 0 \\
\hline Bubulcus_ibis & 8.1 & 3.9 & 23.5 & $\mathrm{~A}$ & 51 & 365.95 & 30 & 60 & 10 \\
\hline Bucephala_clangula & 8 & 9.4 & 30 & $\mathrm{~A}$ & 46 & 918.56 & 10 & 70 & 0 \\
\hline Butorides_virescens & 5.1 & 3.9 & 19 & $\mathrm{~A}$ & 41.5 & 201.5 & 70 & 30 & 0 \\
\hline Calidris_acuminata & 7.4 & 4 & & A & 19.5 & 66.08 & 0 & 80 & 0 \\
\hline Calidris_alpina & 8.1 & 4 & 22 & $\mathrm{~A}$ & 19 & 51.89 & 0 & 80 & 0 \\
\hline Calidris_canutus & 6.8 & 3.5 & 21.5 & $\mathrm{~A}$ & 24 & 141.87 & 10 & 80 & 0 \\
\hline
\end{tabular}




\begin{tabular}{|c|c|c|c|c|c|c|c|c|c|}
\hline Waterbirds & Generation & Clutch & Incubation & Migratory & Size & Mass & DietV & DietInv & Diet: \\
\hline Calidris_ferruginea & 7.6 & 3.8 & 19.5 & $\mathrm{~A}$ & 20.5 & 58.08 & 0 & 80 & 0 \\
\hline Calidris_melanotos & 7.4 & 4 & 22 & $\mathrm{~A}$ & 21 & 79.73 & 0 & 80 & 0 \\
\hline Calidris_minuta & 6.8 & 4 & 20.5 & $\mathrm{~A}$ & 13 & 21.1 & 0 & 70 & 0 \\
\hline Calidris_ruficollis & 7.5 & 4 & 22 & $\mathrm{~A}$ & 14.5 & 26.79 & 0 & 60 & 0 \\
\hline Calidris_subminuta & 7.4 & 4 & & $\mathrm{~A}$ & 14.5 & 30.2 & 0 & 70 & 0 \\
\hline Calidris_temminckii & 6.5 & 4 & 21.5 & A & 14 & 23 & 0 & 90 & 0 \\
\hline Calidris_tenuirostris & 7.4 & 4 & 21 & A & 27 & 192 & 0 & 50 & 0 \\
\hline Casmerodius_albus & 9.1 & 3.9 & 26 & A & 92 & 871.33 & 60 & 40 & 0 \\
\hline Charadrius_alexandrinus & 5 & 3 & 26 & A & 15 & 42.3 & 0 & 100 & 0 \\
\hline Charadrius_asiaticus & 5.8 & 3 & & $\mathrm{~A}$ & 19 & 77.09 & 0 & 80 & 0 \\
\hline Charadrius_dubius & 5 & 4 & 25 & $\mathrm{~A}$ & 15.5 & 38.7 & 0 & 100 & 0 \\
\hline Charadrius_hiaticula & 5.1 & 3.5 & 24 & A & 19 & 64.04 & 0 & 100 & 0 \\
\hline Charadrius_leschenaultii & 5.8 & 3 & 24 & $\mathrm{~A}$ & 22.5 & 74.8 & 10 & 90 & 0 \\
\hline Charadrius_mongolus & 5.2 & 3 & 23 & $\mathrm{~A}$ & 19.5 & 64 & 0 & 100 & 0 \\
\hline Charadrius_veredus & 5.2 & 3 & & $\mathrm{~A}$ & 22 & 95 & 0 & 80 & 0 \\
\hline Chlidonias_hybrida & 9.9 & 2.5 & 19 & $\mathrm{~A}$ & 26 & 83.67 & 60 & 40 & 0 \\
\hline Chlidonias_leucopterus & 9.9 & 2.5 & 20 & $\mathrm{~A}$ & 25 & 54.2 & 20 & 80 & 0 \\
\hline Chlidonias_niger & 8.8 & 2.5 & 21.5 & $\mathrm{~A}$ & 25.5 & 65.3 & 60 & 40 & 0 \\
\hline Ciconia_boyciana & 16.1 & 3.5 & 33 & $\mathrm{~A}$ & 112.5 & 4847.74 & 90 & 10 & 0 \\
\hline Ciconia_nigra & 15.9 & 3.5 & 35 & $\mathrm{~A}$ & 97.5 & 2926 & 90 & 10 & 0 \\
\hline Clangula_hyemalis & 9 & 6.3 & 26.5 & $\mathrm{~A}$ & 48.75 & 871 & 0 & 80 & 0 \\
\hline Cygnus_columbianus & 12.7 & 3.9 & 31.5 & $\mathrm{~A}$ & 135 & 6377.96 & 0 & 0 & 0 \\
\hline Cygnus_cygnus & 12.3 & 4.5 & 35 & $\mathrm{~A}$ & 152.5 & 9349.99 & 0 & 0 & 0 \\
\hline Cygnus_olor & 12.2 & 5.9 & 38 & $\mathrm{~A}$ & 142.5 & 10682.04 & 10 & 10 & 0 \\
\hline Egretta_eulophotes & 6.6 & 3.2 & 23.5 & $\mathrm{~A}$ & 66.5 & 461.83 & 40 & 60 & 0 \\
\hline Egretta_garzetta & 6.6 & 3.5 & 23 & $\mathrm{~A}$ & 60 & 312 & 40 & 60 & 0 \\
\hline Eudromias_morinellus & 6.9 & 3 & 25 & $\mathrm{~A}$ & 21 & 108.16 & 0 & 70 & 0 \\
\hline Fulica_atra & 7 & 7.7 & 23.5 & $\mathrm{~A}$ & 37.5 & 717.12 & 30 & 10 & 0 \\
\hline Gallicrex_cinerea & 4.4 & 4.2 & 24 & $\mathrm{~A}$ & 39.25 & 390.39 & 0 & 30 & 0 \\
\hline Gallinago_gallinago & 4.8 & 4 & 19 & $\mathrm{~A}$ & 26 & 112.94 & 0 & 80 & 0 \\
\hline Gallinago_megala & 4.8 & 4 & & $\mathrm{~A}$ & 28 & 121 & 0 & 80 & 0 \\
\hline Gallinago_solitaria & 4.8 & 4 & & $\mathrm{~A}$ & 30 & 140.11 & 0 & 100 & 0 \\
\hline Gallinago_stenura & 4.8 & 4 & 20 & $\mathrm{~A}$ & 26 & 113 & 0 & 80 & 0 \\
\hline Gallinula_chloropus & 5.9 & 5.8 & 19.5 & $\mathrm{~A}$ & 34 & 339.63 & 20 & 20 & 0 \\
\hline Gelochelidon_nilotica & 11.7 & 2.5 & & $\mathrm{~A}$ & 38 & 218.25 & 50 & 50 & 0 \\
\hline Glareola_maldivarum & 7.3 & 2.4 & & $\mathrm{~A}$ & 24 & 75.2 & 0 & 100 & 0 \\
\hline Grus_grus & 13.4 & 2 & 29.5 & $\mathrm{~A}$ & 107.5 & 5499.99 & 20 & 10 & 0 \\
\hline Grus_japonensis & 12.3 & 2 & 31.5 & $\mathrm{~A}$ & 145 & 8785.99 & 40 & 20 & 0 \\
\hline Grus_leucogeranus & 13 & 2 & 28 & $\mathrm{~A}$ & 140 & 5913.44 & 30 & 10 & 0 \\
\hline Grus_monacha & 12 & 2 & 28.5 & $\mathrm{~A}$ & 95.5 & 3729.9 & 20 & 10 & 0 \\
\hline Grus_nigricollis & 13 & 2 & 32 & $\mathrm{~B}$ & 115 & 5999.99 & 40 & 20 & 0 \\
\hline Grus_vipio & 13 & 2 & 30 & A & 125 & 4662.99 & 10 & 20 & 0 \\
\hline Grus_virgo & 11.2 & 2 & 25 & $\mathrm{~A}$ & 95 & 1500 & 10 & 20 & 0 \\
\hline Haematopus_ostralegus & 13.7 & 3 & 30 & $\mathrm{~A}$ & 40 & 526 & 10 & 90 & 0 \\
\hline Heteroscelus_incanus & 5.7 & 4 & 24 & $\mathrm{~A}$ & 27.5 & 108.24 & 20 & 80 & 0 \\
\hline Himantopus_himantopus & 7.3 & 3.2 & 25.5 & $\mathrm{~A}$ & 37.5 & 176.82 & 0 & 100 & 0 \\
\hline Hydrophasianus_chirurgus & 4.8 & 4 & & $\mathrm{~A}$ & 48.5 & 160.03 & 0 & 60 & 0 \\
\hline Hydroprogne_caspia & 12.2 & 2 & 26.5 & $\mathrm{~A}$ & 50.5 & 655 & 90 & 0 & 10 \\
\hline Ibidorhyncha_struthersii & 9.6 & 4 & & $\mathrm{~B}$ & 40 & 294 & 10 & 90 & 0 \\
\hline Ixobrychus_cinnamomeus & 4.1 & 3.9 & & $\mathrm{~A}$ & 40.5 & 126.49 & 70 & 30 & 0 \\
\hline
\end{tabular}




\begin{tabular}{|c|c|c|c|c|c|c|c|c|c|}
\hline Waterbirds & Generation & Clutch & Incubation & Migratory & Size & Mass & DietV & DietInv & Diets \\
\hline Ixobrychus_eurhythmus & 4.1 & 4.2 & 17 & $\mathrm{~A}$ & 37.5 & 139 & 70 & 30 & 0 \\
\hline Ixobrychus_minutus & 4.1 & 4.2 & 18.5 & $\mathrm{~A}$ & 32.5 & 99.49 & 30 & 70 & 0 \\
\hline Ixobrychus_sinensis & 4.1 & 4.6 & 18.5 & $\mathrm{~A}$ & 35 & 94.29 & 20 & 80 & 0 \\
\hline Larus_argentatus & 13 & 2.5 & 29 & $\mathrm{~A}$ & 61 & 1090.99 & 50 & 30 & 20 \\
\hline Larus_brunnicephalus & 11.5 & 3 & 24 & $\mathrm{~A}$ & 43 & 569.29 & 50 & 30 & 10 \\
\hline Larus_canus & 9.8 & 3 & 25 & $\mathrm{~A}$ & 43 & 412.53 & 40 & 40 & 10 \\
\hline Larus_crassirostris & 11.5 & 2.5 & 24.5 & A & 47 & 561 & 40 & 30 & 30 \\
\hline Larus_ichthyaetus & 12.4 & 2 & 25 & $\mathrm{~A}$ & 66 & 1378.84 & 70 & 20 & 0 \\
\hline Larus_minutus & 10.5 & 2.4 & 24 & $\mathrm{~A}$ & 27.5 & 118 & 20 & 80 & 0 \\
\hline Larus_relictus & 6 & 2.4 & 25 & $\mathrm{~A}$ & 44 & 490.2 & 60 & 40 & 0 \\
\hline Larus_ridibundus & 9.6 & 1.7 & 24 & $\mathrm{~A}$ & 40 & 284 & 20 & 70 & 0 \\
\hline Larus_saundersi & 11.5 & 3 & & $\mathrm{~A}$ & 30.5 & 198 & 40 & 60 & 0 \\
\hline Larus_schistisagus & 11.5 & 3 & 29 & $\mathrm{~A}$ & 61 & 1323 & 40 & 30 & 20 \\
\hline Limicola_falcinellus & 4.8 & 4 & 21.5 & $\mathrm{~A}$ & 17 & 37.1 & 0 & 80 & 0 \\
\hline Limnodromus_semipalmatus & 5.8 & 2 & 22 & $\mathrm{~A}$ & 34.5 & 212 & 40 & 60 & 0 \\
\hline Limosa_lapponica & 8.9 & 4 & 20.5 & $\mathrm{~A}$ & 39 & 291.65 & 0 & 80 & 0 \\
\hline Limosa_limosa & 8.6 & 4 & 23 & $\mathrm{~A}$ & 40 & 288.37 & 20 & 60 & 0 \\
\hline Lymnocryptes_minimus & 5.4 & 4 & 22.5 & $\mathrm{~A}$ & 18 & 50.07 & 0 & 80 & 0 \\
\hline Melanitta_fusca & 7.5 & 7.9 & 27.5 & $\mathrm{~A}$ & 54.5 & 1800.17 & 10 & 80 & 0 \\
\hline Mergellus_albellus & 5.7 & 7.9 & 27 & $\mathrm{~A}$ & 39.5 & 608.55 & 20 & 70 & 0 \\
\hline Mergus_merganser & 7.3 & 9.8 & 31 & $\mathrm{~A}$ & 65 & 1451.02 & 90 & 10 & 0 \\
\hline Mergus_serrator & 7.3 & 8.9 & 31.5 & $\mathrm{~A}$ & 55 & 1015.17 & 70 & 20 & 0 \\
\hline Mesophoyx_intermedia & 5.6 & 3.5 & 21 & $\mathrm{~A}$ & 64 & 458.83 & 80 & 20 & 0 \\
\hline Netta_rufina & 7 & 8.9 & 27 & $\mathrm{~A}$ & 55.5 & 1118 & 0 & 0 & 0 \\
\hline Numenius_arquata & 5 & 4 & 28 & $\mathrm{~A}$ & 55 & 802.99 & 0 & 40 & 0 \\
\hline Numenius_madagascariensis & 10.1 & 4 & 16 & $\mathrm{~A}$ & 59.5 & 792 & 0 & 90 & 0 \\
\hline Numenius_minutus & 10.1 & 4 & 22.5 & $\mathrm{~A}$ & 31 & 173 & 0 & 80 & 0 \\
\hline Numenius_phaeopus & 9.1 & 4 & 25 & $\mathrm{~A}$ & 43 & 364.57 & 0 & 60 & 0 \\
\hline Nycticorax_nycticorax & 8.8 & 3.9 & 22.5 & $\mathrm{~A}$ & 60.5 & 810 & 70 & 30 & 0 \\
\hline Pelecanus_crispus & 11 & 2 & 32 & $\mathrm{~A}$ & 170 & 9512.09 & 100 & 0 & 0 \\
\hline Pelecanus_philippensis & 15.4 & 3.5 & 30 & $\mathrm{~A}$ & 139.5 & 5010.98 & 100 & 0 & 0 \\
\hline Phalacrocorax_carbo & 11.3 & 3.5 & 29 & $\mathrm{~A}$ & 90 & 2528.97 & 90 & 10 & 0 \\
\hline Phalaropus_fulicarius & 9.9 & 4 & & A & 38.5 & 308 & 0 & 100 & 0 \\
\hline Phalaropus_lobatus & 4.9 & 4 & 21.5 & A & 21 & 36.68 & 0 & 80 & 0 \\
\hline Philomachus_pugnax & 4.9 & 4 & 19 & $\mathrm{~A}$ & 18.5 & 35.5 & 0 & 80 & 0 \\
\hline Platalea_leucorodia & 7.2 & 3.5 & 24.5 & $\mathrm{~A}$ & 82.5 & 1228 & 20 & 70 & 0 \\
\hline Pluvialis_fulva & 5.6 & 4 & 23.5 & $\mathrm{~A}$ & 24.5 & 250 & 0 & 70 & 0 \\
\hline Pluvialis_squatarola & 6 & 4 & 26.5 & $\mathrm{~A}$ & 29 & 84.11 & 0 & 70 & 0 \\
\hline Podiceps_auritus & 7.1 & 4.5 & 23.5 & $\mathrm{~A}$ & 34.5 & 730.96 & 60 & 40 & 0 \\
\hline Podiceps_cristatus & 7.1 & 3.9 & 28 & $\mathrm{~A}$ & 53.5 & 575 & 70 & 30 & 0 \\
\hline Podiceps_grisegena & 7.1 & 4.5 & 22.5 & $\mathrm{~A}$ & 45 & 1646 & 50 & 50 & 0 \\
\hline Podiceps_nigricollis & 7.1 & 3.5 & 22 & $\mathrm{~A}$ & 31 & 320.69 & 20 & 80 & 0 \\
\hline Porzana_fusca & 2.7 & 5.2 & 20 & $\mathrm{~A}$ & 22 & 49.7 & 0 & 40 & 0 \\
\hline Porzana_pusilla & 2.7 & 6.6 & 18 & $\mathrm{~A}$ & 18 & 61.06 & 10 & 70 & 0 \\
\hline Rallus_aquaticus & 4.6 & 8.1 & 22 & $\mathrm{~A}$ & 26.5 & 162.11 & 40 & 20 & 0 \\
\hline Recurvirostra_avosetta & 8.7 & 3.5 & 24 & $\mathrm{~A}$ & 43.5 & 325 & 10 & 80 & 0 \\
\hline Rissa_tridactyla & 12.9 & 2 & 26 & $\mathrm{~A}$ & 39 & 706 & 50 & 30 & 0 \\
\hline Rostratula_benghalensis & 8.6 & 3.2 & 18 & $\mathrm{C}$ & 25.5 & 76.6 & 0 & 60 & 0 \\
\hline Scolopax_rusticola & 6.3 & 4 & 17.5 & A & 34 & 205 & 0 & 70 & 0 \\
\hline Sterna_albifrons & 10.9 & 2.5 & 22.5 & $\mathrm{~A}$ & 25 & 94.69 & 60 & 40 & 0 \\
\hline
\end{tabular}




\begin{tabular}{llllllllll}
\hline Waterbirds & Generation & Clutch & Incubation & Migratory & Size & Mass & DietV & DietInv & Diets \\
\hline Sterna_hirundo & 11.5 & 2 & 25 & $\mathrm{~A}$ & 35.5 & 53.8 & 80 & 10 & 10 \\
Tachybaptus_ruficollis & 5.4 & 3.7 & 22.5 & $\mathrm{~A}$ & 27 & 3450 & 20 & 80 & 0 \\
Tadorna_ferruginea & 10.9 & 8.5 & 28.5 & $\mathrm{~A}$ & 66 & 885.22 & 10 & 10 & 0 \\
Tadorna_tadorna & 10.9 & 8.9 & 29.5 & $\mathrm{~A}$ & 62.5 & 1418.68 & 20 & 70 & 0 \\
Tringa_erythropus & 5.6 & 4 & & $\mathrm{~A}$ & 30.5 & 77.5 & 20 & 80 & 0 \\
Tringa_glareola & 5.2 & 4 & 22.5 & $\mathrm{~A}$ & 21 & 158 & 0 & 100 & 0 \\
Tringa_nebularia & 6.3 & 4 & 24 & $\mathrm{~A}$ & 32.5 & 71.4 & 20 & 80 & 0 \\
Tringa_ochropus & 5.6 & 4 & 21.5 & $\mathrm{~A}$ & 22.5 & 48.4 & 20 & 70 & 0 \\
Tringa_stagnatilis & 5.6 & 4 & & $\mathrm{~A}$ & 24 & 129 & 20 & 60 & 0 \\
Tringa_totanus & 6.2 & 4 & 25.5 & $\mathrm{~A}$ & 28 & 62.1 & 20 & 80 & 0 \\
Vanellus_cinereus & 8.9 & 4 & 28.5 & $\mathrm{~A}$ & 35.5 & 165 & 0 & 100 & 0 \\
Vanellus_vanellus & 9 & 4 & 25.5 & $\mathrm{~A}$ & 29.5 & 198 & 0 & 100 & 0 \\
Xenus_cinereus & 6.4 & 4 & 23.5 & $\mathrm{~A}$ & 23.5 & 123 & 0 & 60 & 0 \\
\hline
\end{tabular}

Appendix S2 Data of the 35 lakes and reservoirs used in this study.

\begin{tabular}{lllllll}
\hline lake name & No. of waterbirds species & Productivity $\left(\mathrm{mg} . \mathrm{m}^{-3)}\right.$ & FRic & Latitude & Longitude & Lake area $(\mathrm{h}$ \\
\hline Wuliangsuhai & 96 & 11.36 & 0.096254 & 40.93 & 108.83 & 29300.00 \\
Hasuhai & 51 & 8.36 & 0.055521 & 40.6 & 110.98 & 4161.54 \\
Dalinuoer & 99 & 3.30 & 0.104735 & 43.25 & 116.42 & 38536.07 \\
Erdos & 72 & 10.13 & 0.092827 & 36.71 & 109.31 & 1717.43 \\
Chagannaoer & 72 & 72.92 & 0.089553 & 43.43 & 114.92 & 3300.00 \\
Wulagai & 103 & 4.62 & 0.097590 & 46.06 & 119.57 & 22600.00 \\
Juyanhai & 40 & 2.62 & 0.064184 & 42.33 & 101.25 & 4000.00 \\
Daihai & 43 & 25.35 & 0.063914 & 40.55 & 112.66 & 2420.00 \\
Khorchin & 66 & 69.42 & 0.082376 & 45.08 & 122.18 & 18047.04 \\
Hangjinnaoer & 55 & 18.32 & 0.072142 & 40.5 & 108.96 & 1600.00 \\
Naihai Wetland & 55 & 96.95 & 0.073630 & 40.53 & 110.01 & 1308.25 \\
Honggou reservoir & 4 & 14.60 & 0.000051 & 38.84 & 105.67 & 160.00 \\
Sand Lake & 74 & 11.43 & 0.079616 & 38.62 & 106.33 & 8602.23 \\
Habahu & 45 & 10.07 & 0.067270 & 37.83 & 107.28 & 240.00 \\
Mingcuihu & 74 & 14.85 & 0.083680 & 38.38 & 106.37 & 492.00 \\
Yuehai & 37 & 39.34 & 0.060880 & 38.57 & 106.21 & 1070.37 \\
Xinghaihu & 24 & 55.21 & 0.037125 & 38.99 & 106.41 & 3283.91 \\
Tianhu & 24 & 6.65 & 0.037125 & 38.02 & 105.74 & 591.00 \\
Hongjiannao & 74 & 1.75 & 0.082940 & 39.1 & 109.88 & 3330.00 \\
Kusaihu & 9 & 0.41 & 0.017198 & 35.73 & 92.83 & 32600.00 \\
Goulucuohu & 9 & 0.49 & 0.022734 & 34.6 & 92.47 & 2350.00 \\
Zhuonaihu & 8 & 0.51 & 0.012421 & 35.55 & 91.95 & 16300.00 \\
Yanhu & 9 & 0.51 & 0.018675 & 35.53 & 93.42 & 1120.00 \\
Chaganhu & 94 & 40.00 & 0.089094 & 45.26 & 124.29 & 51936.54 \\
Hengshuihu & 113 & 16.30 & 0.100239 & 37.69 & 115.58 & 18787.00 \\
Cuihu & 56 & 15.00 & 0.068850 & 40.08 & 116.17 & 166.00 \\
Alagou & 8 & 1.06 & 0.008048 & 42.85 & 87.36 & 94.00 \\
Bosten Lake & 58 & 8.98 & 0.082285 & 41.67 & 86.9 & 94529.19 \\
Heshilike & 17 & 51.07 & 0.017170 & 41.75 & 85.69 & 525.00 \\
Kongquehe & 17 & 39.62 & 0.017170 & 41.25 & 86.5 & 79.25 \\
Kenadaliya & 17 & 5.76 & 0.05170 & 38.61 & 86.29 & 69.90 \\
Taitemahu Lake & 31 & 6.65 & 39.48 & 88.29 & 26930.42 \\
& & & & & &
\end{tabular}




\begin{tabular}{lllllll}
\hline lake name & No. of waterbirds species & Productivity $\left(\mathrm{mg} . \mathrm{m}^{-3)}\right.$ & FRic & Latitude & Longitude & Lake area $(\mathrm{h}$ \\
\hline Ayakekumuhu Lake & 21 & 2.74 & 0.046644 & 37.52 & 89.79 & 98800.00 \\
Miyun Reservior & 113 & 3.55 & 0.102017 & 40.48 & 116.83 & 18800.00 \\
Yehahu Lake & 105 & 5.79 & 0.089492 & 40.46 & 115.84 & 441.00 \\
\hline
\end{tabular}

Appendix A1 Map of the CMW (the community-level weighted means of trait values) for the percentage of foraging on ground in the 35 surveyed lakes. Background is the 3D representation of the surface (hillshade).

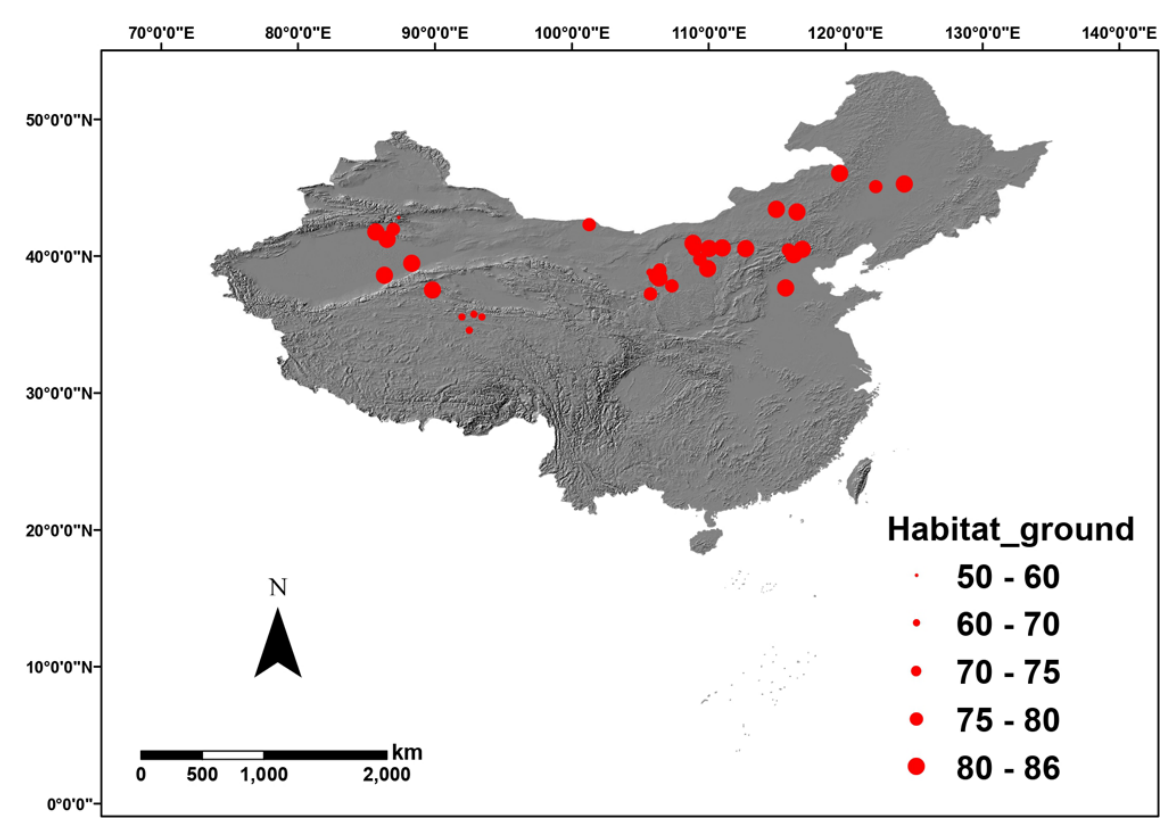

Appendix A2 Map of the CMW (the community-level weighted means of trait values) of percent use of plant materials. Background is the $3 \mathrm{D}$ representation of the surface (hillshade). 

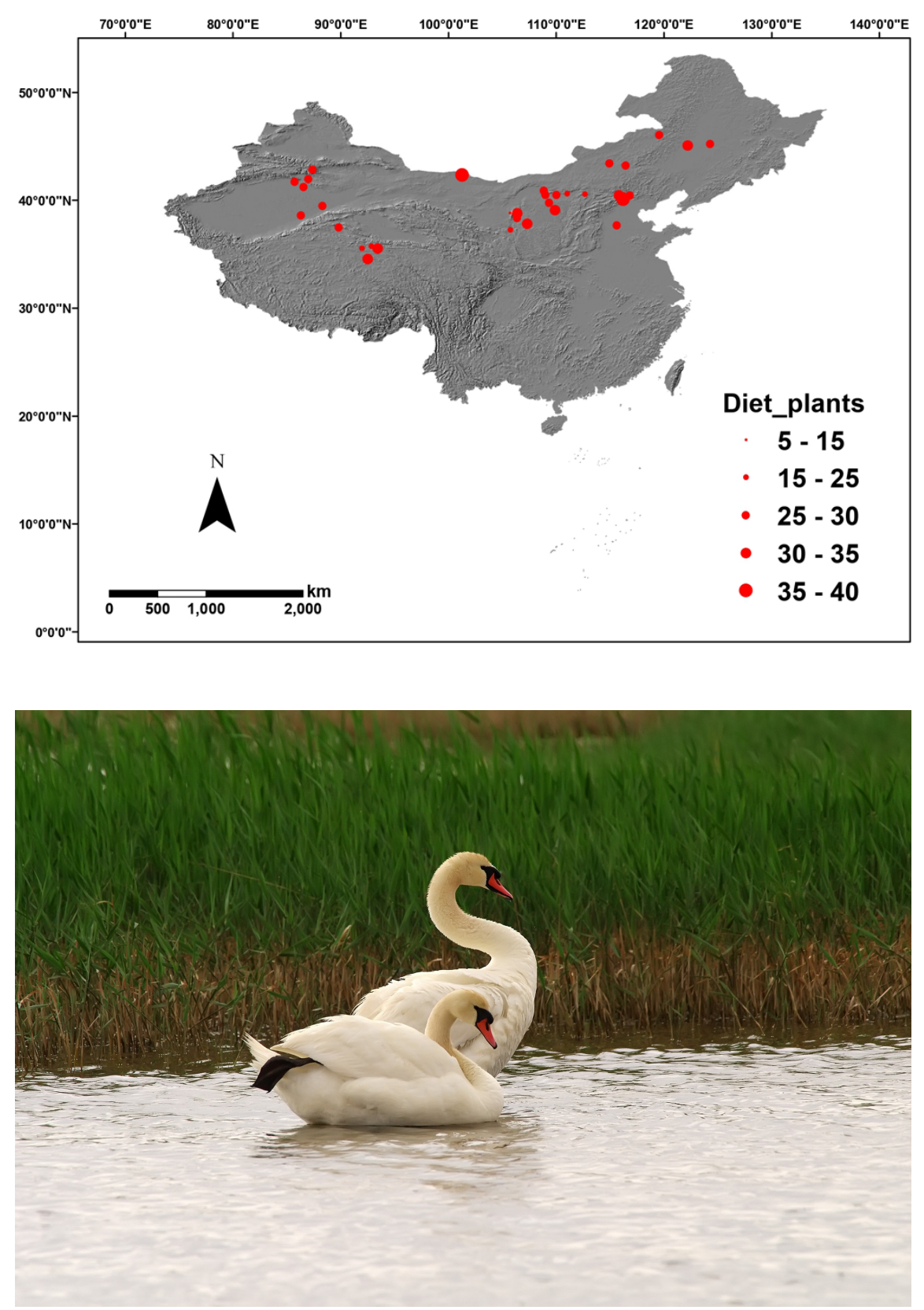


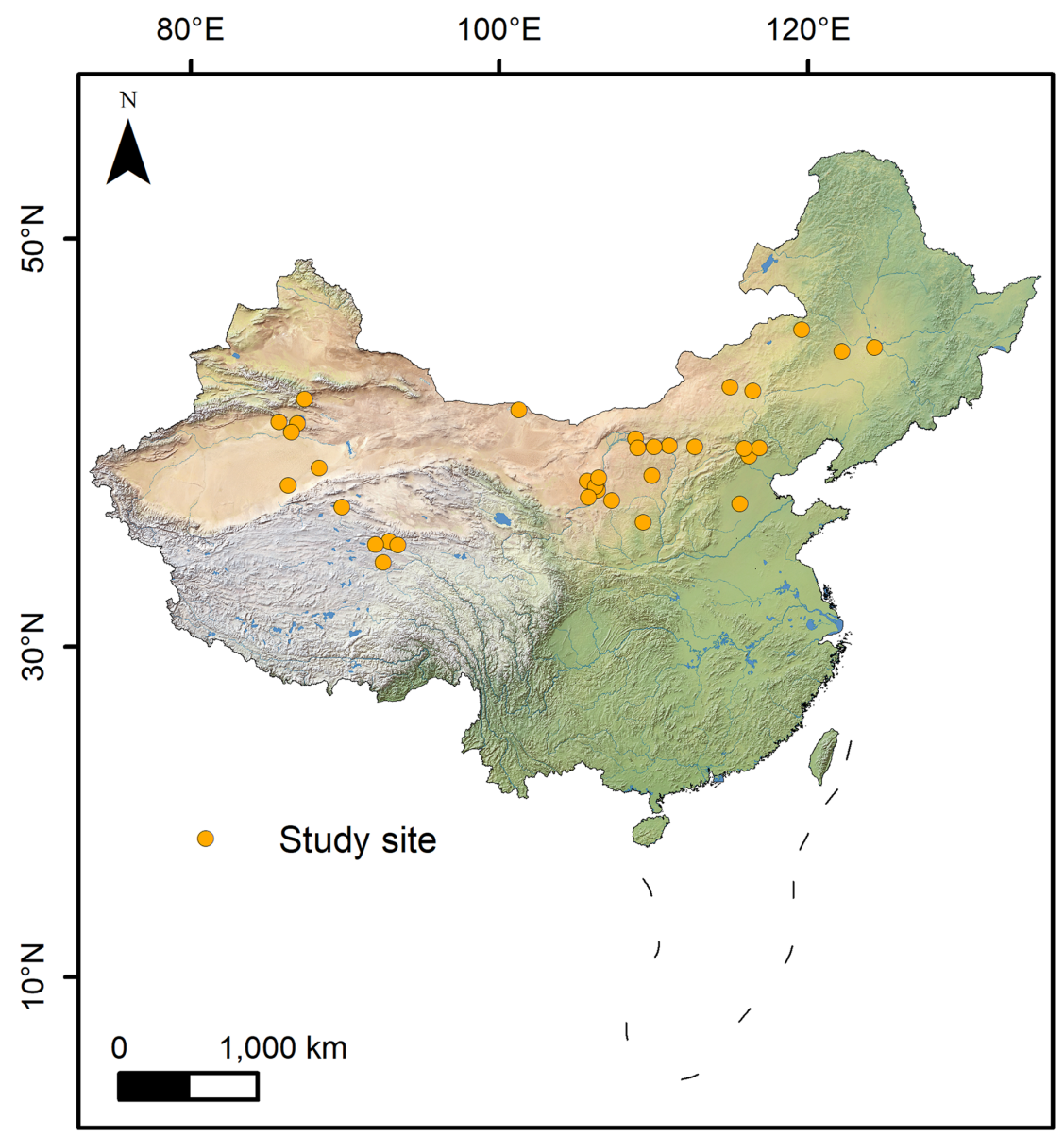


a Waterbirds species richness

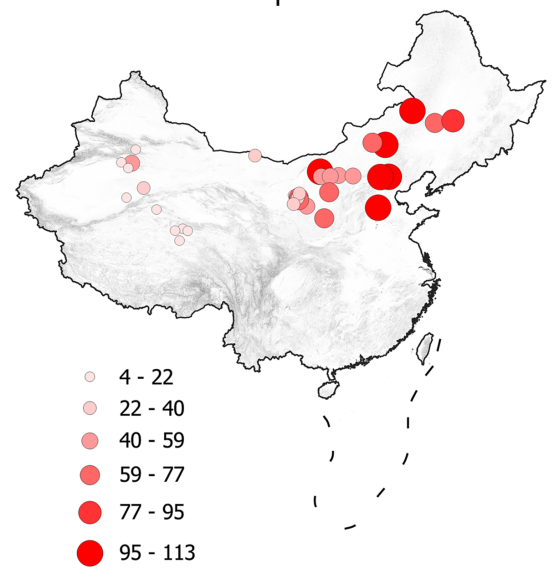

c Lake productivity

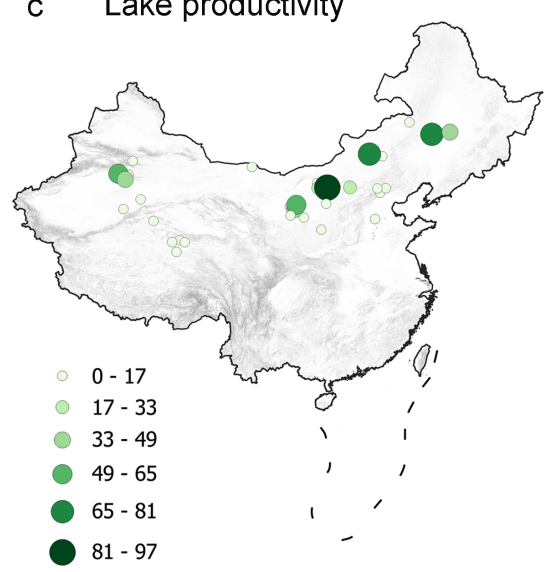

b Waterbrids functional richness

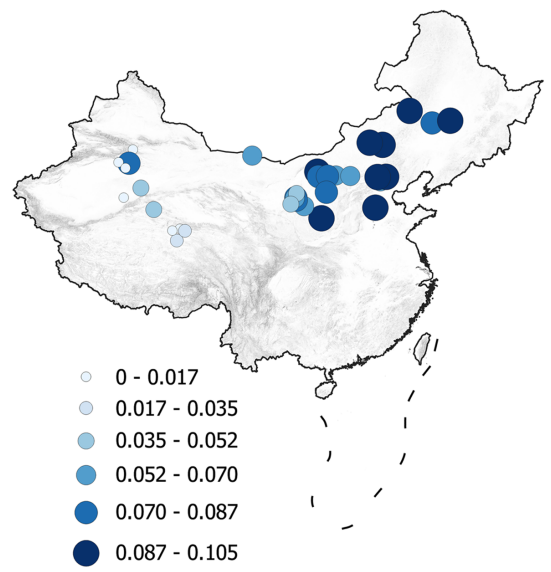

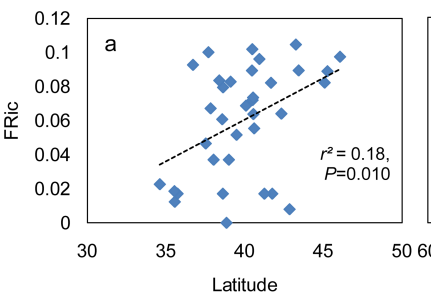
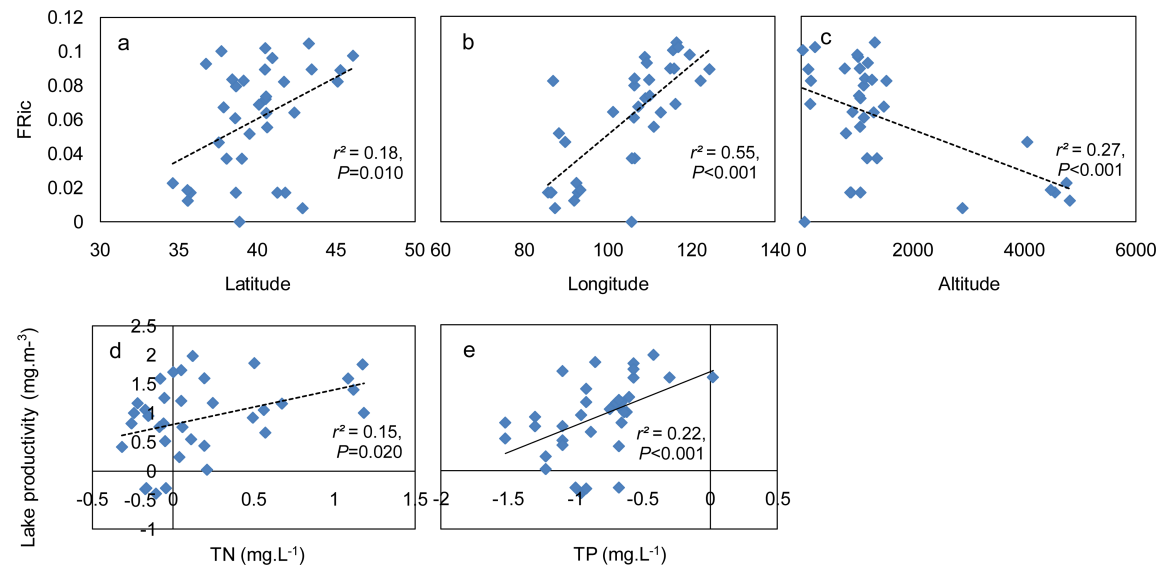

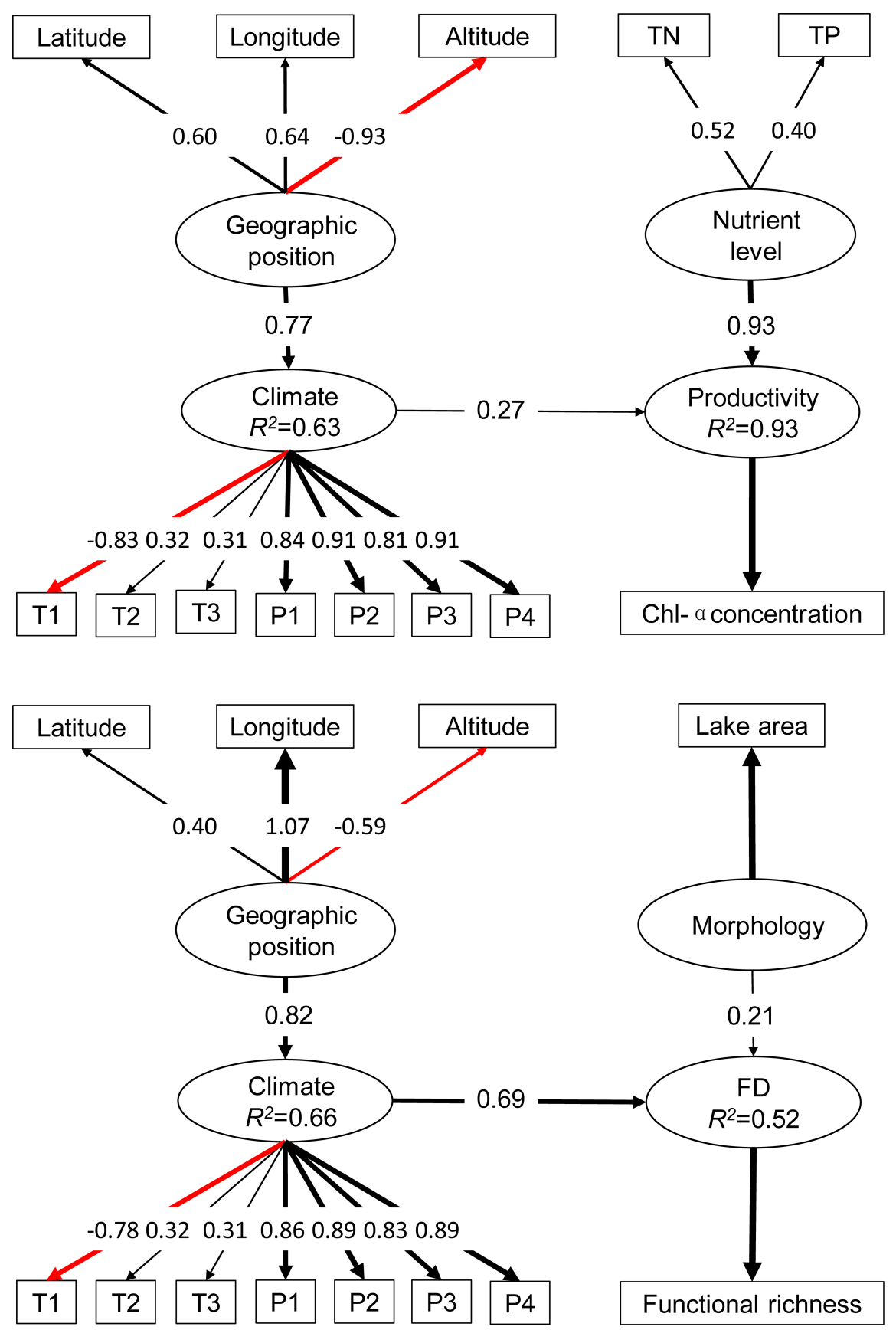


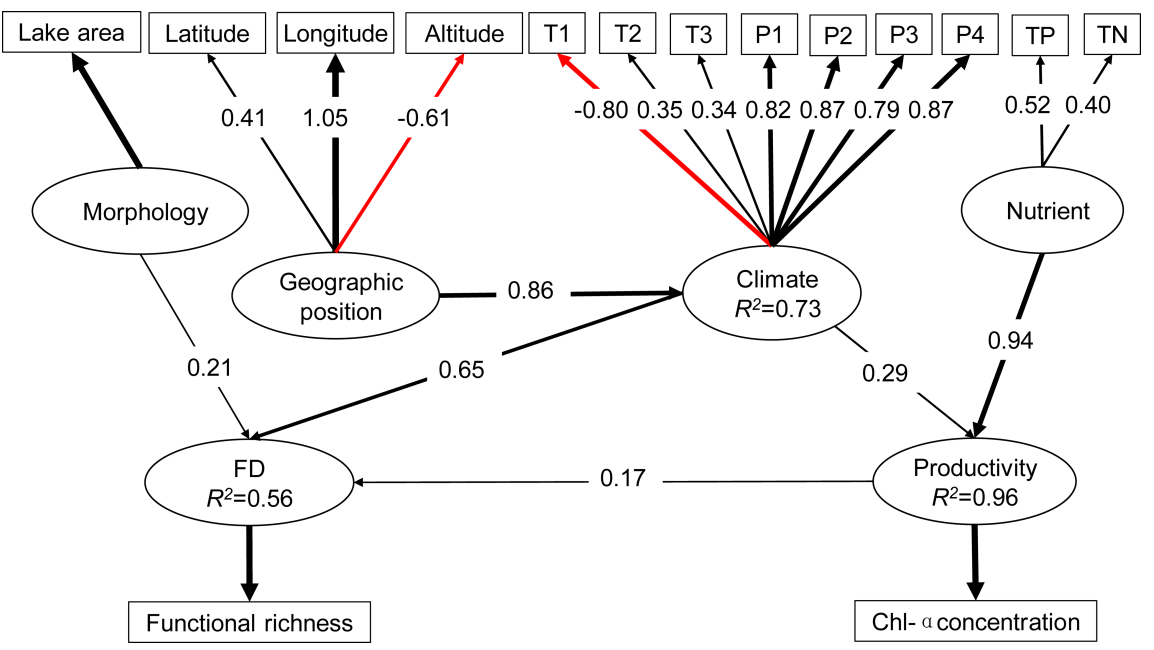

